LA-UR-97- 4912

November 1997

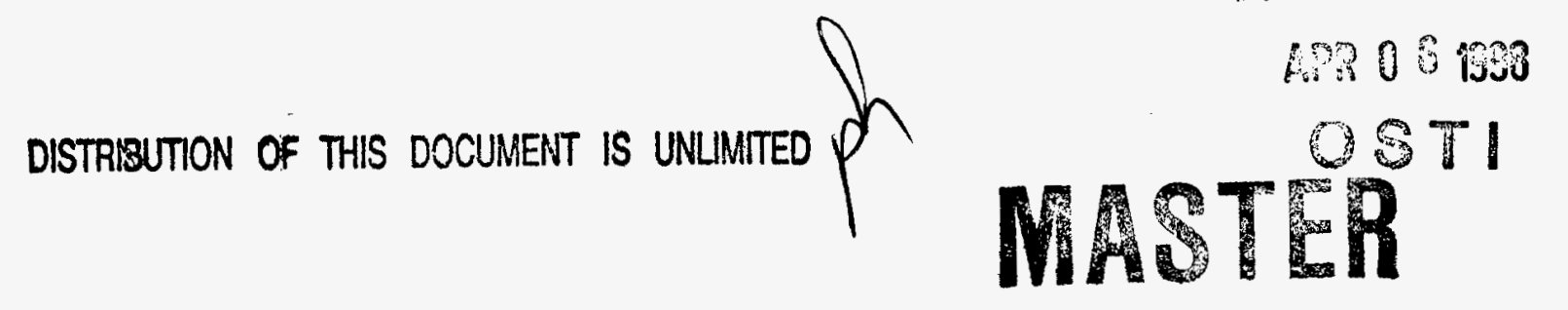

EVALUATION OF MITIGATION STRATEGIES IN FACILITY GROUP 1 DOUBLE-SHELL FLAMMABLE-GAS TANKS AT THE HANFORD SITE

Cetin Unal, Pratap Sadasivan,

William L. Kubic, and James R. White

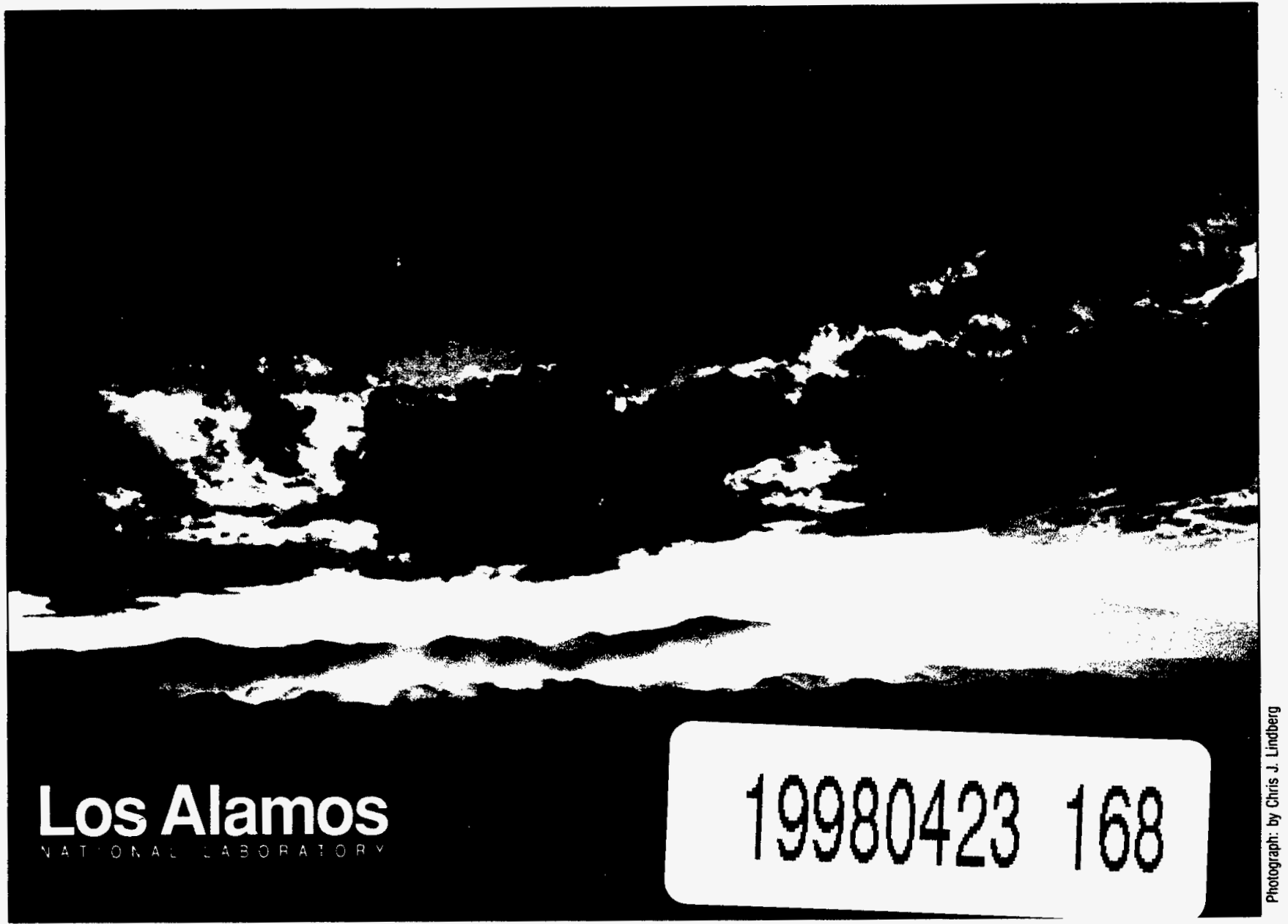

Los Alamos National Laboratory, an affirmative action/equal opportunity employer, is operated by the University of California for the U.S. Department of Energy under contract W-7405-ENG-36. By acceptance of this article, the publisher recognizes that the U.S. Govemment retains a nonaxclusive, royalty-free license to publish or reproduce the published form of auspices of the U.S. Department of Energy. Los Alamos National Laboratory strongly supports academic freedom and a researcher's right to publish; therefore, the Laboratory as an institution does not endorse the viewpoint of a publication or guarantee its technical correctness. 


\section{DISCLAIMER}

This report was prepared as an account of work sponsored by an agency of the United States Government. Neither the United States Government nor any agency thereof, nor any of their employees, makes any warranty, express or implied, or assumes any legal liability or responsibility for the accuracy, completeness, or usefulness of any information, apparatus, product, or process disclosed, or represents that its use would not infringe privately owned rights. Reference herein to any specific commercial product, process, or service by trade name, trademark, manufacturer, or otherwise does not necessarily constitute or imply its endorsement, recommendation, or favoring by the United States Government or any agency thereof. The views and opinions of authors expressed herein do not necessarily state or reflect those of the United States Government or any agency thereof. 


\title{
EVALUATION OF MITIGATION STRATEGIES IN FACILITY GROUP 1 DOUBLE- SHELL FLAMMABLE-GAS TANKS AT THE HANFORD SITE
}

\author{
by \\ C. Unal, P. Sadasivan, B. Kubic, and J. R. White
}

February 1998

Los Alamos National Laboratory

Technology and Safety Assessment Division

Nuclear Systems and Design Group, TSA-10

Los Alamos, NM 87545 


\section{INTRODUCTION}

NEED TITLE, ABSTRACTRadioactive nuclear waste generated by the production and purification of plutonium at the Hanford. Site currently is stored in underground waste storage tanks at the site. The tanks were built in clusters and designated as "tank farms." These farms fall into two main categories: farms that contain single-shell tanks (SSTs) and farms that contain double-shell tanks (DSTs). The SSTs are concrete tanks with a single steel liner lying across the bottom and sides. The DSTs are concrete tanks with a full steel liner that provides the primary containment and a second steel liner around the bottom and sides. There are a total of 149 SSTs and 28 DSTs.

The wastes stored in the tanks are chemically complex. They basically involve various sodium salts (mainly nitrite, nitrate, carbonates, aluminates, and hydroxides), organic compounds, heavy metals, and various radionuclides, including cesium, strontium, plutonium, and uranium. The waste is typically classified as sludge, salt cake, supernatant liquid, and crust. A waste tank may contain one or more of these waste types.

The waste stored in all Hanford tanks is known to generate flammable gas (FG) [(hydrogen, ammonia, and a small amount of hydrocarbons (such as methane)] by complex chemical reactions. In addition, nitrous oxide and ammonia also may be produced in some tanks. Typically, the rate of generation of FG is low; thus, if the gas is released continuously into the headspace, the concentrations can be maintained at relatively low levels [below $25 \%$ of the lower flammability limit (LFL)] by providing adequate ventilation. Typically, the process of gas generation, retention, and release is transient: that is, the volume of retained gas in the tank continues to increase with time up to a point. After this stage, different tanks behave differently. Some tanks reach a quasi-steady state when gas generation is balanced by the release rate. Other tanks show continuous cycles of retention followed by episodic releases. Many of the DSTs and SSTs exhibit this latter pattern.

Hazards related to the steady release of gases can be managed effectively by ensuring adequate ventilation flow rates through the dome space. However, episodic releases are more difficult to manage. Episodic releases of gases can occur naturally as a result of density instabilities or can be induced by intrusive operations (such as water lancing or core sampling) or by external events (such as earthquakes).

The existence of flammable concentrations of gas in the dome space or in the ventilation system, concurrent with the availability of oxidizer and an ignition source, defines the FG hazard. These conditions could cause the pressure to exceed structural limits, which in turn could result in unacceptable structural damage to the tank and release of radioactive material.

The FG hazard was first declared an Unreviewed Safety Question (USQ) in Tank SY101. Johnson (Ref. 1) gives a good summary of the status and history of the FG USQ 
and developments after 1990. Currently, there exists a Flammable Gas Watch List (FGWL) that includes about 25 tanks. The FG USQ is still applicable to all FGWL tanks except Tank SY-101. The USQ on Tank SY-101 was closed by a separate study requiring the implementation of necessary safety controls. The FG USQ was redefined in 1996 and encompassed a wider spectr am of issues and faci'ties. There. is a continuing effort to close the FG USQ on FGWL tanks. The present study is in support of USQ closure efforts.

\subsection{Scope of Work}

Currently, removing a tank from the FGWL requires establishing conditions for the tank that prevent it from releasing the volume of gas that, if ignited, would result in the pressure exceeding the structural limit. The necessary safe conditions can be established in several ways:

- mitigation of gas generation,

- mitigation of gas retention,

- mitigation of gas release,

- mitigation of ignition sources,

- mitigation of available oxidizer for the combustion, and

- demonstration of the fact that the declared safety issue is not real and did not exist.

In 1992, a preliminary study was performed to identify concepts for the mitigation and/or remediation of the hydrogen gas generation, storage, and periodic release. The study concentrated on Tank SY-101. Babad et. al. (Ref. 2) summarizes the findings and recommendations of this effort. The study limited itself to identification of mitigation strategies without detailed performance evaluations because of the lack of sufficient data, analysis, and analysis tools. This study is summarized in Sec. 2. The leading candidates for mitigation strategies that were identified in this study were assessed further in 1994, and the results are documented in Ref. 3. However, the focus was again on Tank SY-101. As has already been noted, the FG USQ has been closed for Tank SY-101; the focus of the present work is on the remaining DSTs on the FGWL. These tanks are categorized as Facility Group I Tanks in Ref. 4. In this report, we use the abbreviation "FG-1 tanks" to refer to these tanks. The set of FG-1 tanks includes Tanks AN-103, AN-104, AN-105, AW-101, and SY-103.

Over the past few years, considerable additional knowledge and experience have been gained on various aspects of waste behavior in the Hanford waste tanks. This is especially true for the FG-1 tanks. Our knowledge of the mechanisms of gas 
generation, retention, and release has been extended by experimental and analytical studies between 1992 and the present. These studies are summarized in Ref. 1. Additional analysis tools also have been developed. Although there still are considerable uncertainties in results obtained from predictive tools, it is prudent to reevaluate various mitigation strategies in the light of the newly available data and tools.

The objective of this report therefore is to evaluate the possible mitigation strategies to eliminate the FG hazard and safety issue on FGWL tanks, as described above. The evaluation is an engineering study of "mitigation" concepts for FG generation, retention, and release behavior in FG-1 DSTs (SY-101, AN-103, AN-104, AN-105, and AW-101).

The specific objective is the qualitative engineering evaluation of the effect of mitigation concepts on gas generation, gas retention, and gas release. Where possible, limited quantification of the effects of mitigation strategies on the FG hazard also is considered. The results obtained from quantification efforts discussed in this report should be considered as best-estimate values. No attempt is made to determine the uncertainty in the quantified parameters. Results and conclusions of this work are intended to help in establishing methodologies in the contractor's controls selection analysis to develop necessary safety controls for closing the FG USQ. The general performance requirements of any mitigation scheme are discussed in the next section.

\subsection{Performance Requirements of Mitigation Strategy}

The ultimate goal of mitigation is to eliminate the FG safety hazard. Reducing the severity or intensity of the FG hazard as a result of applying a mitigation strategy is a desirable effect and is part of the ultimate goal. The mitigation strategies identified in this report are at different stages of conceptual design and technology development. Some of them may not provide a means to eliminate the FG hazard completely. However, they provide a means to maintain the average FG concentration in the dome space and at the exhauster header at less than $25 \%$ of the LFL of the FG mixture. They provide a means to control the gas release and generation rates to yield no FG hazard in the tank dome space while tanks await waste retrieval.

Reference 2 established detailed safety and technical guidelines for mitigation and remediation strategies. These guidelines have been reviewed and adapted for this work.

The primary goal of a proposed mitigation strategy is to prevent FG concentrations from exceeding $25 \%$ of the LFL of the hydrogen/nitrous oxide/ammonia mixtures. The following list gives the performance requirements for mitigation strategies.

- FG concentrations exceeding $25 \%$ of the LFL in the tank dome or at the ventilation header (in a volume-averaged sense) must be prevented; 
- The release of toxic or radiological substances that exceed limit specifications for applicable codes and standards must be prevented;

- A negative pressure in the dome space must be maintained;

- An uncontrolled reaction in the gas or waste matrix must be prevented;

- The tank $\mathrm{pH}$ must be maintained within waste storage specifications;

- Conditions in the tank must be maintained to avoid foreclosing any realistic mitigation, retrieval, and/or disposal options;

- Irreversible mitigation options must not be prescribed unless they place the tank in a passively safe status;

- The need for overt actions (e.g., system should be passive, minimizing the need for human intervention) must be minimized;

- Ease of maintenance and operation must be maintained;

- The structural integrity of the tank must be maintained;

- The application of stresses or loads to the tank and ancillary support structures that exceed operating specifications must be prevented; and

- Build-up of energetic or gas-producing materials in the tank must be avoided and/or prevented.

There are several other criteria from the operational point of view. Although these are considered to have secondary effects in our evaluation, they are important and can be summarized as follows:

- The mitigation strategy should make the tank behavior more predictable,

- The mitigation strategy should include acceptable surveillance, and

- The mitigation strategy should allow surveillance equipment to be upgraded.

The above criteria are used as safety and technical guidelines in our evaluation of mitigation strategies identified in this report.

Section 2 is a brief review of previous work (Refs. 2 and 3). Section 3 describes the FG-1 tanks, tank data, and tank history and status. Section 4 discusses the methodology and process of evaluating mitigation strategies. Section 5 summarizes 
the analysis frame work (i.e., gas generation, retention and release mechanism). Section 6 is the summary of the brief description of identified mitigation strategies. Section 7 is the results preliminary ranking methodology. Detail discussion of evaluation of each mitigation concept are provided in Section 8. The mitigation strategi s studied in Section 8 are re-ranked by considering the conclusions of analysis for final decisions for recommendation. Final ranking and recommendations are presented in Section 9. 


\section{PREVIOUS WORK ON MITIGATION STRATEGIES}

This section provides a brief summary of previous work performed at Hanford on mitigation strategies for the ${ }^{5} \mathrm{G}$ safety issue. Only a brief overview of the process is presented here; the different mitigation concepts considered are discussed in more detail later in this report (see Sec. 6).

\subsection{Preliminary Evaluation of Concepts}

The first systematic consideration of possible mitigation and remediation strategies was undertaken in 1991. Possible strategies were classified into three categories: ultrasonic agitation, waste mixing, and chemical treatment concepts. Three working groups were established to consider each of these categories in detail and identify different approaches in each category. These approaches then were evaluated using a qualitative decision methodology and leading candidates were recommended for engineering evaluations. The results of the evaluations are documented in Ref. 2; a brief summary is provided in this section.

\subsubsection{Identification of Concepts}

As a first step in the process of identifying mitigation concepts, a set of safety and technical guidelines were developed. All proposed concepts had to conform to these general guidelines. The main guidelines were that the scheme should

- prevent spontaneous gas release episodes,

- maintain negative pressure in the dome space,

- not preclude future retrieval or disposal options, and

- not cause uncontrolled reactions in the dome or waste.

In addition, several guidelines restated operating specification requirements. The full list of guidelines is available in Sec. 4.3 of Ref. 2.

The working groups identified 19 mitigation and 3 remediation concepts. Four mitigation concepts utilized the idea of ultrasonic agitation, nine utilized mixing of the waste, and six used the chemical treatment concept. All three identified remediation concepts used chemical treatment to achieve the purpose. The various concepts are listed below.

* Ultrasonic Agitation

- Compression waveguides,

- Piezoelectric transducer in waste,

- Coupling of sound through tank wall, and

- Liquid whistles. 
* Waste Mixing

- Dilution,

- Horizontal jet mixing,

- Vertical jet mixing with draft tube and downward flow,

- Vertical jet mixing with draft tube and upward flow,

- Liquid piston,

- Nitrogen sparging,

- Circulation by mechanical stirring,

- Circulation by turnover of the nonconvective layer, and

- Removal of supernatant liquid.

* Chemical Treatment Methods for Mitigation

- Heating waste to below atmospheric boiling,

- Alter nonconvective layer rheology by chemical addition,

- Surfactant addition,

- Heating waste briefly to above atmospheric boiling,

- Cooling the waste, and

- Lowering of waste $\mathrm{pH}$.

* Chemical Treatment Methods for Remediation

- Separation of selected components,

- Destruction of organics, and

- Addition of mineral-forming agents.

\subsubsection{Preliminary Evaluation of Concepts}

The various concepts in each category were evaluated using a qualitative decision methodology, and the leading concepts in each category were identified for further engineering studies. The details of the evaluations are provided in Ref. 2.

Eight judgment factors were used to qualitatively assess the various concepts. Each scheme was rated on a scale of 1 to 5 (with 1 being the least favorable and 5 being the most favorable) on each of the eight judgment factors. Weighting factors were used to assign varying degrees of importance to the judgment factors. The judgment factors and their corresponding weighting factors are

- Confidence in effectiveness of proposed technology (weight $=3$ ),

- Assessment of achievable risk reduction (weight $=3$ ), 
- Implementation risk (weight $=3$ ),

- Complexity of data and modeling needs (weight $=2$ ),

- Implementation time (weight $=2$ ),

- Operating time to achieve successful mitigation or remediation (weight = 2),

- Complexity of maintenance, operation, and surveillance (weight $=1$ ), and

- Risk affecting disposal options (weight $=1$ ).

For each scheme, the weighted scores for the eight factors were summed to obtain an overall score. The highest scoring concepts in each of the three mitigation and remediation categories were identified for further engineering evaluations.

\subsubsection{Recommended Concepts}

The leading concepts that emerged from the decision methodology described above are

- Dilution of the waste,

- Heating of the waste to a temperature less than the atmospheric boiling point,

- Mixing of the waste using various types of pumping concepts, and

- Ultrasonic agitation using compressional waveguides.

It was also suggested in Ref. 2 that the above mitigation options were compatible with each other; therefore, more than one approach could be used concurrently. For example, a combination of dilution and heating or a combination of dilution and ultrasonic agitation are possible mitigation approaches.

\subsubsection{Discussion}

Several points related to the above process need to be noted. First, the process was undertaken at a time when the FG hazard in Tank SY-101 was the most pressing safety issue at Hanford. Tank SY-101 had been exhibiting periodic releases of a mixture of hydrogen, nitrous oxide, ammonia, methane, and other gases, and flammable limits were known to have been exceeded during several of these release episodes. As a result, the identification of mitigation strategies focused primarily on Tank SY-101. 
Secondly, the decision methodology used to compare the various mitigation concepts had to rely on limited characterization data available at that time. As noted in the Introduction section in Ref. 2, the rankings of the various alternative concepts are likely to be different if they are reevaluated based on updated charact $r$ ization data. In light of considerable additional characterization work that has been completed in the DSTs since 1991, a reevaluation of the original concepts would be desirable. In addition, the vastly improved knowledge of the mechanisms of gas generation, retention, and release in the DSTs, as well as field experience, may point to additional and perhaps simpler possible mitigation approaches. This is the purpose of the present study.

The next section summarizes previous work on the assessment of mitigation concepts. Again, it should be noted that considerable additional knowledge has been gained since the assessment work summarized here was performed. The following discussion is included here mainly to provide an overview of the mitigationspecific experimental data and analyses that currently are available. Individual tank characterization data that may be used to develop new models for mitigation concepts are covered in Sec. 3.

\subsection{Further Assessment of Mitigation Concepts}

The four leading mitigation concepts identified in Ref. 2 and listed in the previous section were evaluated further in 1994. The results of this study are documented in Ref. 4. This section provides a brief summary of the assessment results from Ref. 4.

The various methods were assessed to varying degrees. This was mainly because of the differences in the state of development of the four concepts at the time. The pump mixing mixer-pump? mitigation concept had proceeded to full-scale in-tank testing in Tank SY-101 by 1993. The ultrasonic agitation concept was replaced with sonification (for reasons that are discussed in Sec. 2.2.2), and some preliminary work on the design of a sonic probe had been completed by 1994 . However, key elements of data required for the quantitative evaluation of heating and for dilution concepts were still unavailable.

\subsubsection{Pump Mixing}

The efficacy of a mixer pump in preventing episodic gas releases has been demonstrated in Tank SY-101. Intermittent mixing of the waste reduces the retention of gas in the waste and results in a more sustained release of the gas. Lower retention implies a lower headspace concentration in the event of a gas release episode.

The waste level and the dome space hydrogen concentration are monitored continuously in this tank. No episodic releases have occurred in this tank since the pump was deployed in July 1993. Intermittent pump operation, typically less than three runs per week with each run lasting less than an hour, has kept background hydrogen concentrations below $25 \%$ of the LFL. The waste level has been 
maintained at low values and within allowable limits. No evidence of severe adverse effects has been observed. However there is a concern that a region beyond the radius of the temperature probes [multifunction instrument trees (MITs)] may not be disturbed by jet mixing. In fact, consolidation of heavy particles may alter the retentiun characteristics of the undisturbed region. The current status of the undisturbed region is unkown.

Despite the obvious success of the mixer pump in eliminating gas release events (GREs) in Tank SY-101, the possible extension of the concept to other FG-1 (FG1) tanks (see Ref. 4 for a discussion of the Facility Group classification scheme) does not appear to be straightforward. Although several numerical and analytical studies of jet mixing phenomena in Tank SY-101 were undertaken before pump deployment (Refs. 5 and 6 for example), no significant mechanistic modeling had been done since then. In addition, the region of influence of the jet pump in Tank SY-101 has not been established definitively. Reference 4 cites a radius of influence of $28 \mathrm{ft}$, but the basis for this is not stated. Also, there was no attempt to quantify the radius of influence by obtaining necessary measurements of velocity or other analytical or experimental methods. The shape of zone of influence is not verified by measured data. Recently, a few additional studies have been documented (Refs. 7 and 8 for example).

The importance of material properties such as sludge yield strength and viscosity have been established in a qualitative manner; however, quantitative chardcterization of the combined influence of the dominant parameters has not been performed. Therefore, although additional material property data have become available for FG1 DSTs, the application of jet mixing to these tanks requires additional work. A set of qualitative criteria for consideration in applying jet mixing concepts to other tanks is presented in Ref. 3.

\subsubsection{Sonic Probe}

As discussed in Sec. II.12.1?, the original mitigation concepts proposed by the mitigation working groups in 1992 involved ultrasonic agitation. The concept is based on the theory that gas retention in the waste can be reduced by using pressure waves to yield the waste???produce?. When the waste is yielded, the bubbles can rise up through the waste by buoyant forces and be released into the dome space. Thus, intermittent deployment of ultrasonic agitation devices would result in a more continuous release of gas and lower retention. In subsequent studies, it was found that ultrasonic frequencies resulted in unacceptable attenuation by the small bubbles in the waste. Therefore, it was concluded in Ref. 3 that ultrasonic probes would be feasible only if multiple probes were deployed at different locations in the waste. A sonic probe (using frequencies of 40 to $150 \mathrm{~Hz}$ ) was chosen as the mitigation scheme for further study.

The preliminary design of a sonic probe was completed in 1994. The design uses a cylindrical shell $18 \mathrm{ft}$ long and $11 \mathrm{in}$. in diameter, with an eccentric mass that rotates about a shaft. The design frequency is $\sim 100 \mathrm{~Hz}$. 
In addition, a considerable number of experimental and analytical studies on various aspects of the sonic probe were carried out in 1993 and 1994. Different experimental studies relating to sonification used different media. Proof-ofprinciple experiments were carried out using vibrators in a tube filled with wet concrete. Experiments werc conducted using wasia simulants and actual tank waste from Tank SY-101 to investigate possible densification or strengthening as a result of sonification. Most experiments showed decreased strength over time, but at least one experiment showed that hardening is possible. Thus, this issue must be considered unresolved. Naturally, the effects on waste in other tanks are also highly uncertain.

The ability of sonic probes to degasify a material with yield strength and which contains retained gas was confirmed in experiments using a cornmeal simulant. However, rheological properties of the cornmeal simulant were considerably different from those of the waste in Tank SY-101, and thus, the applicability of the experimental results to waste in Tank SY-101 and certainly to the waste in other tanks is dubious.

The analytical and computational studies relating to sonification of waste involved several idealizations and assumptions. Some computational analyses were also carried out for Tank SY-103. These studies also provide supporting evidence that the principle works. However, many critical assumptions used in the analyses are unverified, and thus, these studies do not necessarily improve our ability to predict the effects of sonification in Tank SY-101, Tank SY-103, or in the other tanks. Specifically, Ref. 3 cited the leading uncertainties as follows.

- The mechanism of waste yielding by sonification and the criteria for yielding are not known.

- The attenuation characteristics as a function of the frequency are not known. The attenuation of the waves in the waste is a function of several parameters, including the bubble diameter. The range of bubble diameters in the waste remains highly uncertain. Therefore, the volume of sludge that can be yielded using this approach cannot be estimated with any degree of accuracy.

- Possible side effects of sonification, such as densification, hardening, foaming, or adverse chemical reactions, are unknown.

By 1994, the success of the mixer pump in mitigating the episodic releases of FG in Tank SY-101 led to the discontinuation of further developmental efforts on the sonic probe. As a result, the key drawbacks listed above remain unresolved. 


\subsubsection{Dilution}

The premise behind this mitigation scheme is that dilution decreases the solids fraction in the nonconvective layer and thus red"ces gas retention. Lower retention implies that gas is released more continuously, and episodic releases are prevented. The idea that dilution decreases the solids fraction is intuitive and has been demonstrated in limited experiments. However, the effects of dilution on gas retention have not been verified. Reference 3 contains a preliminary analysis of the effects of dilution on the waste and the potential for mitigation by dilution. At the time that Ref. 3 was being developed, most of the available waste characterization data pertained to Tank SY-101. Thus, the discussion in Ref. 3 of dilution as a mitigation scheme focused exclusively on Tank SY-101.

Quantitative prediction of the effects of dilution on gas release behavior requires a quantitative understanding of several issues. First, the waste inventory before dilution should be known, and it should be possible to determine the waste inventory after dilution. For this, the effects of dilution on the solids fraction must be known. This in turn requires accurate solubility models for the major solid constituents in the waste. These constituents include nitrates, nitrites, carbonates, and aluminates. Second, the effect of the change in waste inventory on the waste strength and viscosity must be known. Third, the effect of changes in rheology on the gas retention must be known. In addition, the effect of the change in solids fraction on gas generation also should be knowin.

Reference 3 discusses limited experimental data and analytical modeling of the effects of dilution on gas releases. The analyses used an empirical correlation for the effect of dilution ratio on the dissolution fraction (the fraction of solids that are dissolved by the diluent). This correlation was based on data obtained from dilution experiments with Tank SY-101 waste.

In one analysis discussed in Ref. 3, neutral buoyancy gas release volumes before and after dilution were compared. The results showed that the addition of diluent tends to increase gas release volumes. However, this analysis considered only the effects of increased hydrostatic pressure (assuming that diluent is added and that no waste is transferred out of the tank), decreased liquid density, and decreased solids fraction as a result of dilution. The effects of reduced gas retention were not considered because the calculated gas releases are based on neutral buoyancy.

Another model discussed in Ref. 3 considered dilution of Tank SY-101 waste, together with transfer of waste to a second tank. The effects of dilution on gas retention again were not considered; calculated gas releases and dome space concentrations were based on neutral buoyancy conditions.

In summary, data and analyses available to characterize dilution effects on gas releases are extremely limited. A small database exists for the effect of dilution on waste properties such as solids fraction, viscosity, and yield strength. However, its 
applicability is limited to Tank SY-101. Limited analyses have been carried out for the effects of dilution on gas releases in Tank SY-101. Since Ref. 3 was published, a host of additional characterization data have become available. This these data?will enable a considerably more detailed consideration of dilution. Improved solubility models and a better understanding of the relationship between di.ution and gas retention are essential if dilution is to be considered as a mitigation option for other tanks. In addition, possible long-terms effects of dilution must be considered.

\subsubsection{Heating}

Heating is considered as a possible mitigation scheme because it could cause most of the sodium salts to dissolve. This reduction in the solids fraction is believed to would result in lower gas retention, although the principle has not been verified by experiment. Mitigation by heating has not been analyzed to any significant degree either. Reference 4 presents largely qualitative observations on possible effects of heating on gas generation and gas retention.

Since Ref. 3 was published, a host of additional characterization data have become available. This these data?will enable a considerably more detailed consideration of heating. Improved solubility models, including temperature effects, and a better understanding of the relationship between solids fraction and gas retention are essential if heating is to be considered as a mitigation option for other tanks.

\subsection{Summary}

This section presents a summary of previous work relating to mitigation strategies. Various mitigation concepts identified by a set of working groups in 1991 were listed, and the decision methodology used to rank the concepts was discussed. The leading candidates for mitigation concepts were identified to be

- pump mixing,

- ultrasonic agitation,

- dilution, and

- heating.

These concepts subsequently were investigated further to varying degrees, and the results were documented in a 1994 report.need reference Data and analyses available to address these concepts were discussed. The main points are as follows:

- The efficacy of the mixing approach for mitigation has been demonstrated by the success of the mixer pump in eliminating the episodic GREs in Tank SY-101. However, very little data or analyses are available to facilitate direct extension of the method to other tanks.

- Design of a sonic probe for deployment in Tank SY-101 was completed. The ability of sonic probes to degasify a material with yield strength and 
which contains retained gas has been confirmed in experiments with simulants, but applicability tank waste has not been established. Some analyses of sonic effects on waste have been performed, but the analyses involved many idealizations and assumptions (such as the yielding criteria) that remain unverified.

- Effects of dilution on the waste viscosity and strength have been studied experimentally using waste samples from Tank SY-101. However, the data are very limited, and the results are of limited applicability. Improved solubility models and a better understanding of the relationship between dilution and gas retention are required.

- Heating as a mitigation scheme has very little experimental or analytical supporting evidence. Although heating the waste will reduce the solids fractions, a host of other related issues, including the effects on gas generation and gas retention, are poorly understood.

Over the past few years, a considerable amount of additional knowledge and experience has been gained about various aspects of waste behavior in the Hanford tanks. This section was intended mainly to provide an overview of previously identified candidates for gas release mitigation and for the mitigation-specific experimental data and analyses that currently are available. Individual tank characterization data obtained in recent years may point to additional mitigation concepts and also could be used to develop new analyses. This is the subject of the remainder of this report. 


\section{DESCRIPTION OF FACILITY GROUP 1 TANKS}

As discussed in Sec. 1, the objective of this report is to evaluate possible mitigation strategies to eliminate the FG-hazard in the FGWL tanks. The specific focus is on FG-1 tanks. Various possible mitigation schemes identified in a preliminary step will be ranked on the basis of several criteria, and the most promising ones will be carried forward for further engineering evaluations. This section presents a summary of available data and other relevant information on the FG-1 tanks. It is intended to serve as a common database for the subsequent discussions and quantitative evaluations of the mitigation schemes.

\subsection{Tank Description}

Five tanks currently are categorized as FG-1 tanks: AN-103, AN-104, AN-105, AW101, and SY-103. All of these tanks are DSTs. The AN tanks started receiving waste in 1981, Tank AW-101 in 1980, and Tank SY-103 in 1977. This section provides a brief description of the DSTs.

\subsubsection{Geometrical information}

The DST design consists of a primary tank, a secondary tank, and a steel-reinforced concrete shell that surrounds both tanks. Figure 3-1 shows the cross section of Tank AN-104. Although the overall?waste level and the thickness of the convective and nonconvective layers vary from tank to tank, the cross section of the other FG-1 tanks is similar to that shown in Fig. 3-1.

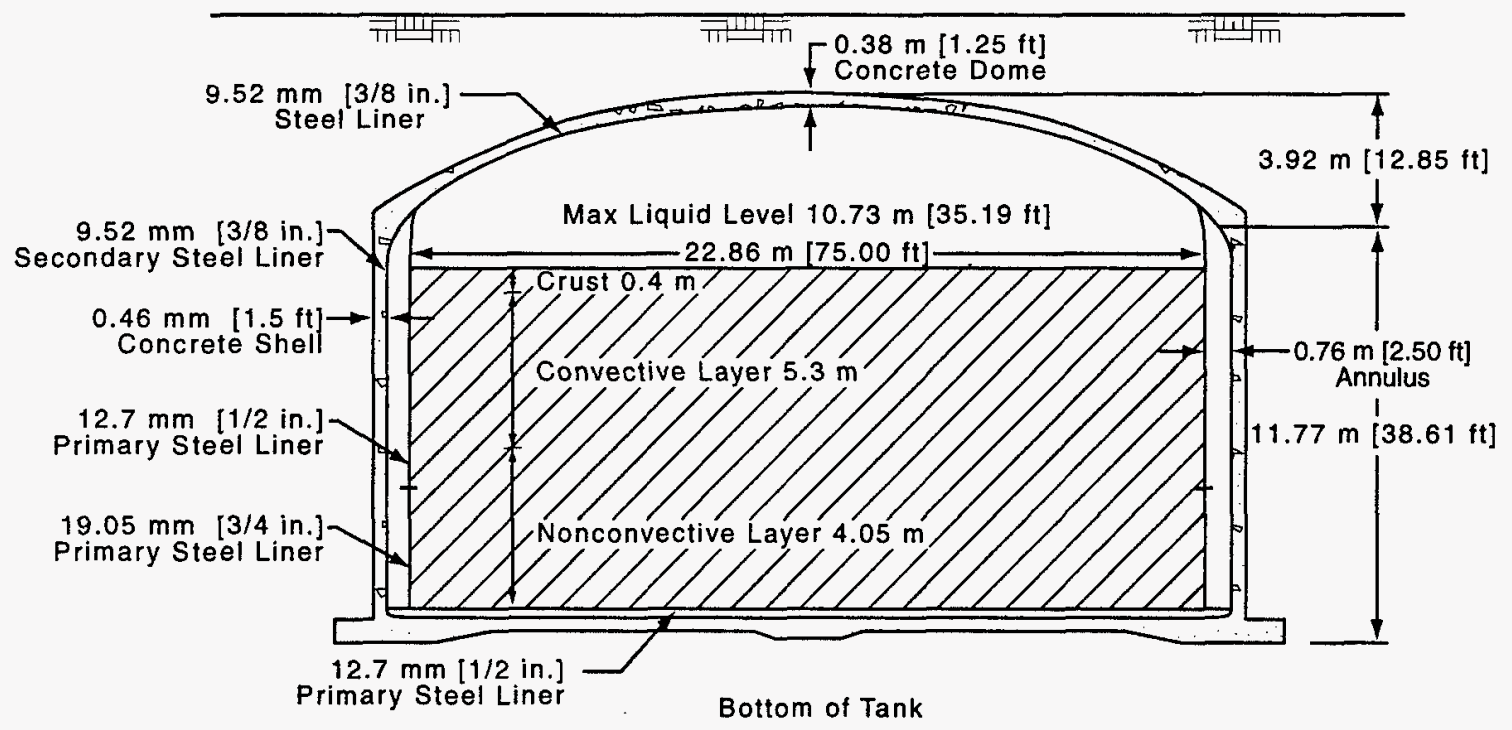

Fig. 3.1. Typical cross-sectional view of a DST (Tank AN-104 is shown). 
The DSTs are fabricated as three concentric tanks. The free-standing primary tank is $75 \mathrm{ft}$ in diameter and $46 \mathrm{ft}, 9 \mathrm{in}$. in diameter at the crown. The primary tank sits on a concrete insulating pad. The secondary tank is $80 \mathrm{ft}$ in diameter and creates an annulus around the primary tank. The secondary tank sits on a concrete structural pad. The completely enclosed annulus, which is -entilated, serves as a containment barrier for potential leaks in the primary tank. A concrete shell completely encases the secondary tank and the tank dome, as shown in Fig. 3-1. It the shell?provides additional containment, radiation shielding, and structural support and rests on a concrete foundation.

Tanks AN-103, AN-104, AN-105, and AW-101 have a minimum capacity of 1.15 Mgal and a maximum capacity of $1.16 \mathrm{Mgal}$. Tank SY-103 has a minimum capacity of $991.5 \mathrm{kgal}$. and a maximum capacity of $1.0 \mathrm{Mgal}$. The type and volume of waste currently estimated to be present in these tanks are discussed in Sec. 3.1.3. An additional discussion of the historical tank contents and current inventory is provided in Sec. 3.3.

\subsubsection{Risers}

Each tank is equipped with riser pipes that penetrate the concrete dome and the primary and secondary tank. The risers provide access to the annulus and to the primary tank interior for waste transfer operations and for equipment installation? and monitoring. Figure 3-2 is a plan view of Tank AN-104 and shows the locations of the various risers. Ris $\epsilon_{i}$ locations differ from tank to tank, but Fig. 3-2 is typical of the other FG-1 tanks as well.

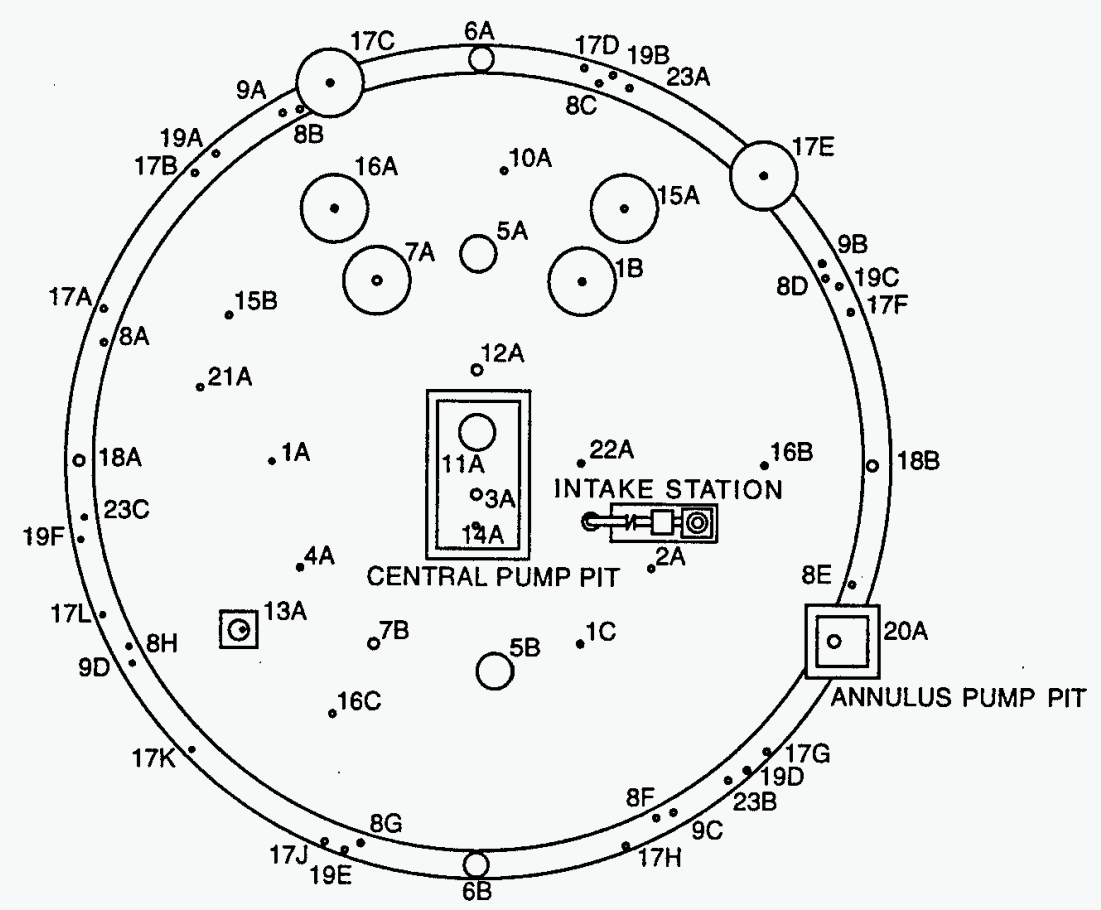

Fig. 3-2. Typical plan view of a tank (Tank AN-104 is shown). 
Most of the risers in each tank acurrently re in use. Some have been used to introduce equipment such as supernatant pumps and slurry distributors into the waste, others are used to introduce monitoring equipment such as thermocouples and pressure gauges into the tank interior, and yet others are used as observation ports or for ventilation. Each tank has a few spar 2 risers.

Many of the mitigation strategies considered in Ref. 2 and listed in Sec. 2 involve the introduction of additional equipment into the tank or waste. Therefore, the availability of spare risers is an important consideration in assessing the viability of many mitigation schemes. Table 3-1 provides a summary of the risers on the tanks; the number of spare risers also is listed.

Each of the FG-1 tanks currently has a supernatant pump installed in the 12-in.diam riser of the central pump pit. The central pump pits in Tanks AN-103, AN104, AN-105, and AW-101 each have a slurry distributor installed in a 42-in.-diam riser. All five tanks currently have a color video camera installed in another 42-in.diam riser.

\subsubsection{Waste Inventory}

Table 3-2 lists the estimated volumes and types of waste contained in the FG-1 tanks. ${ }^{9}$ Additional discussion of the waste composition and historical gas release behavior in the tanks is provided in Sec. 3.3.

\subsubsection{Available Tank Data}

As discussed in Sec. 1, several experimental and analytical studies conducted over the past $5 \mathrm{yr}$ have led to considerable improvements in our understanding of gas generation, retention, and release.

TABLE 3-1

STATUS OF RISERS IN FG-1 TANKS

\begin{tabular}{|c|c|c|c|c|c|c|c|c|}
\hline \multirow[b]{2}{*}{ Tank } & \multirow{2}{*}{$\begin{array}{l}\text { Total } \\
\text { No. of } \\
\text { Risers }\end{array}$} & \multirow{2}{*}{$\begin{array}{l}\text { Dome } \\
\text { Risers }\end{array}$} & \multicolumn{2}{|c|}{ 42-in. Risers } & \multicolumn{2}{|c|}{ 12-in. Risers } & \multicolumn{2}{|c|}{ 4-in. risers } \\
\hline & & & Total & Spare & Total & Spare & Total & Spare \\
\hline AN-103 & 59 & 22 & 3 & 1 & $\overline{4}$ & 2 & 15 & 2 \\
\hline $\mathrm{AN}-104$ & 59 & 22 & $\overline{3}$ & 1 & 4 & $\overline{2}$ & 15 & 2 \\
\hline AN-105 & 59 & 22 & 3 & 1 & 4 & 2 & 15 & 1 \\
\hline$\overline{A W-101^{\mathrm{a}}}$ & 64 & 27 & $\overline{3}$ & $\overline{1}$ & 6 & $\overline{4}$ & 15 & $\overline{3}$ \\
\hline SY-103 & 59 & 22 & $\overline{3}$ & 1 & 4 & 1 & 15 & 6 \\
\hline
\end{tabular}

\footnotetext{
${ }^{\mathrm{a}}$ Tank AW-101 also has two 20-in. risers and one 36-in. riser. All are spare.
} 
TABLE 3-2

TYPE OF WASTE AND WASTE VOLUMES

\begin{tabular}{|c|c|c|}
\hline Tank & Type of Waste & Waste Volume (kgal.) \\
\hline AN-103 & Double-shell slurry & 956 \\
\hline AN-104 & Double-shell slurry feed & 1060 \\
\hline AN-105 & Double-shell slurry feed & 1131 \\
\hline AW-101 & Double-shell slurry feed & 1127 \\
\hline SY-103 & Complex concentrate & 753 \\
\hline
\end{tabular}

\subsubsection{Experiments}

Three waste-intrusive devices have been developed and deployed in the FG-1 tanks. The void fraction instrument $(\mathrm{VFI})^{10,11}$ was developed to obtain experimental data to characterize the void fraction at different locations in the waste. The ball rheometer ${ }^{12}$ was developed to obtain experimental data for characterizing the rheological properties of the waste. The device uses the principle of falling-ball rheometry. The ball rheometer also has been used to determine convective-layer densities. The retained gas sampler (RGS) ${ }^{13}$ captures core samples in the waste and was developed to characterize the distribution of retained gas in the waste (the void profile), as well as the composition of the gas. The core samples captured also are analyzed to obtain waste inventories. Data from these various instruments also are used to estimate the thicknesses of the nonconvective and convective layers.

Tanks AN-103, AN-104, and AN-105 were core sampled in 1996. The results of analyses of these samples are documented in Refs. 14,15, and 16, respectively. Grab samples of supernatant liquid from Tank AW-101 were taken in 1990, and the results of analysis are documented in Ref. 17. Core samples were taken in Tank AW-101 in 1996, but analytical results were unavailable at the time this report was prepared. Core samples from the nonconvective layer have been used to determine the density of this layer.

In addition, standard monitoring data, such as waste temperature profiles, waste level, and dome pressure, are available for all tanks. Standard hydrogen monitoring systems (SHMSs) were deployed in these tanks in 1994 and provide continuous records of headspace hydrogen concentrations. (check).

In addition to the measurements described above, experimental studies were conducted using either actual tank waste or simulants to investigate the process of gas generation in tank waste. Experiments with actual tank waste have been limited to Tanks SY-101 and SY-103. However, predictive models for gas generation based on these experimental studies are not available. As will be discussed in Sec. 3.2.5, 
the data reconciliation approach used at Los Alamos National Laboratory (LANL) includes a qualitative model to quantify gas generation rates.

\subsubsection{Experimental Data}

Measured void profiles, apparent viscosity profiles, and yield stress profiles are documented in Ref. 18. A summary of the measured data is provided in Tables 3-3 and 3-4. Only the best-estimate values are listed.

TABLE 3-3

SUMMARY OF MEASURED DATA

\begin{tabular}{|l|c|c|c|c|c|l|}
\hline \multicolumn{1}{|c|}{ Parameter } & AN-103 & AN-104 & AN-105 & AW-101 & SY-103 & \multicolumn{1}{|c|}{ Comments } \\
\hline Waste level (m) & 8.84 & 9.79 & 10.41 & 10.4 & 6.91 & Enraf or FIC gauge reading \\
\hline $\begin{array}{l}\text { Convective-layer } \\
\text { density (kg/m } \text { ( }^{\text {a }}\end{array}$ & 530 & 1440 & 1430 & 1430 & 1470 & Ball rheometer measurements \\
\hline $\begin{array}{l}\text { Nonconvective- } \\
\text { layer density } \\
\left(\mathrm{kg} / \mathrm{m}^{3}\right)\end{array}$ & 1730 & 1590 & 1590 & 1570 & 1570 & From core samples \\
\hline $\begin{array}{l}\text { Nonconvective- } \\
\text { layer void } \\
\text { fraction (\%) }\end{array}$ & 10.7 & 6.2 & 4.2 & 3.8 & 6.4 & $\begin{array}{l}\text { Average of data from VFI } \\
\text { and RGS }\end{array}$ \\
\hline $\begin{array}{l}\text { Nonconvective- } \\
\text { layer thickness } \\
\text { (m) }\end{array}$ & 3.79 & 4.15 & 4.52 & 2.83 & 3.34 & $\begin{array}{l}\text { Average based on rheometer } \\
\text { data, temperature data, and } \\
\text { core samples }\end{array}$ \\
\hline $\begin{array}{l}\text { Crust thickness } \\
\text { (m) }\end{array}$ & 0.92 & 0.4 & 0.3 & 0.64 & 0.2 & $\begin{array}{l}\text { Based on MTT validation } \\
\text { probe data and/or core } \\
\text { samples }\end{array}$ \\
\hline $\begin{array}{l}\text { Convective-layer } \\
\text { thickness (m) }\end{array}$ & 4.13 & 5.24 & 5.59 & 6.93 & 3.37 & $\begin{array}{l}\text { Waste-level crust thickness, } \\
\text { nonconvective-layer } \\
\text { thickness }\end{array}$ \\
\hline
\end{tabular}

a This is not measured directly; it is a derived quantity.

TABLE 3-4

BEST-ESTIMATE GAS COMPOSITION RESULTS FROM RGS DATA (REF.18)

\begin{tabular}{|c|c|c|c|c|c|c|}
\cline { 2 - 7 } \multicolumn{1}{c|}{} & $\mathbf{H}_{2}$ & $\mathbf{N H}_{3}$ & $\mathbf{N}_{\mathbf{2}} \mathbf{O}$ & $\mathbf{C H}_{\mathbf{4}}$ & $\mathbf{N}_{\mathbf{2}}$ & Other \\
\hline Tank & vol \% & vol \% & vol \% & vol \% & vol \% & vol \% \\
\hline AN-103 & 61 & 0.06 & 3.8 & 0.7 & 34 & 0.44 \\
\hline AN-104 & 47 & 0.02 & 19 & 1.8 & 32 & 0.18 \\
\hline AN-105 & 63 & 0.03 & 11 & 0.7 & 25 & 0.27 \\
\hline AW-101 & 31 & 0.02 & 4.3 & 1.9 & 60 & 2.78 \\
\hline SY-103 & 57 & 6 & 12 & 0.37 & 22 & 2.63 \\
\hline
\end{tabular}

${ }^{a}$ The ammonia fraction in Tank SY-103 is based on an assumed release fraction of $6 \%$ caused by exsolution of dissolved ammonia. 


\subsubsection{Waste Temperature}

The data reconciliation study uses only an average waste temperature; it does not consider the axial variations within the waste. Average temperatures in the noncorvective layer have bren calculated using parabolic curve fits of measured temperature data (See Fig. A-11, Ref. 18). The curve fits are reported in Ref. 19. Similarly, the convective-layer temperatures used in Ref. 19 are used here. The curve fits of the nonconvective-layer temperatures are listed in Table 3-5 $\mathrm{z}$ is the axial elevation from the bottom of the tank). Average nonconvective-layer temperatures were determined by integrating these correlations over the thickness determined from the data reconciliation studies. Reference 18 cites average convective-layer temperatures determined from the measured data; these values also are listed in Table 3-5.

\subsubsection{Waste Viscosity}

The data reconciliation process does not model the viscosity of the waste. The raw data are shown in Figs. A-2, A-4, A-6, A-8, and A-10. The data reported in Ref. 18 were curve-fit using the same functional form as in Ref. 19. These correlations are used here to obtain average values of the apparent viscosity. The correlations and the corresponding average apparent viscosity values are listed in Table 3-6.

TABLE 3-5

CÜRVE-FITS FOR NONCONVECTIVE-LAYER TEMPERATURES

\begin{tabular}{|c|c|c|}
\hline Tank & $\begin{array}{c}\text { Nonconvective-Layer Temperature } \\
\text { Variation (K) }\end{array}$ & $\begin{array}{c}\text { Convective-Layer } \\
\text { Temperature (K) }\end{array}$ \\
\hline AN-103 & $307.764+6.11257 \mathrm{z}-1.07766 \mathrm{z}^{2}$ & 316.0 \\
\hline $\mathrm{AN}-104$ & $310.151+7.86066 \mathrm{z}-1.57425 \mathrm{z}^{2}$ & 314.0 \\
\hline $\mathrm{AN}-105$ & $307.126+6.41284 \mathrm{z}-1.20172 \mathrm{z}^{2}$ & 309.7 \\
\hline $\mathrm{AW}-101$ & $307.340+9.14435 \mathrm{z}-2.31730 \mathrm{z}^{2}$ & 312.7 \\
\hline SY-103 & $306.861+5.61732 \mathrm{z}-1.87020 \mathrm{z}^{2}$ & 305.9 \\
\hline
\end{tabular}

TABLE 3-6

CURVE FITS FOR NONCONVECTIVE-LAYER APPARENT VISCOSITY

\begin{tabular}{|c|c|c|}
\hline Tank & $\begin{array}{c}\text { Nonconvective-Layer Viscosity } \\
\text { Curve Fit (Pa-s) }\end{array}$ & $\begin{array}{c}\text { Convective-Layer } \\
\text { Average Viscosity (Pa-s) }\end{array}$ \\
\hline AN-103 & $100 \exp \left[4.5794\left(\mathrm{H}_{\mathrm{NCL}}{ }^{-\mathrm{z}}\right)^{0.17238}\right.$ & 24,600 \\
\hline $\mathrm{AN}-104$ & $100 \exp \left[4.10624\left(\mathrm{H}_{\mathrm{NCL}}-\mathrm{z}\right)^{0.13419}\right.$ & 10,600 \\
\hline $\mathrm{AN}-105$ & $100 \exp \left[4.03348\left(\mathrm{H}_{\mathrm{NCL}}-\mathrm{z}\right)^{0.17803}\right.$ & 12,900 \\
\hline $\mathrm{AW}-101$ & $100 \exp \left[4.2162\left(\mathrm{H}_{\mathrm{NCL}}{ }^{-\mathrm{z}}\right)^{0.22865}\right.$ & 15,900 \\
\hline $\mathrm{SY}-103$ & $100 \exp \left[3.9545\left(\mathrm{H}_{\mathrm{NCL}}-\mathrm{z}\right)^{0.3677}\right.$ & 18,200 \\
\hline
\end{tabular}

${ }^{\mathrm{a}}$ The correlations are for the lower of the viscosity curves shown in the figures in Ref. 18. The average value considers both risers in each tank. $\mathrm{H}_{\mathrm{NCL}}$ is the height of the nonconvective layer (including void). 
Care must be exercised when using the above correlations and the average values derived from them. The apparent viscosity is a function of strain rates and also varies from one riser to another within a tank (spatial variations). Actual strain rates expected during normal behavior of the tank waste are difficult to predict. The above correlations are bas 2 d on rheometry $\mathrm{da}^{+}$. corresponding to relatively low strain rates used during the experimental measurements and forcorresponding to? one of the two risers. Because of the uncertainty in actual strain rates, average viscosity values based on these correlations are recommended only for comparative purposes; the absolute value for any given tank may not be meaningful. Average viscosity values vary by at most a factor of 2 among the FG-1 tanks.

\subsubsection{Yield Stress}

The data reconciliation process does not model the viscosity of the waste. The raw data are shown in Figs. A-2, A-4, A-6, A-8, and A-10. The nonconvective-layer yield stress varies between 50 and $200 \mathrm{~Pa}$ for the $\mathrm{AN}$ and $\mathrm{AW}$ tanks. The upper-bound yield stress reaches $\sim 300 \mathrm{~Pa}$ in Tank SY-103. The yield stress is related directly to the apparent viscosity data (and the strain rates); therefore, the yield stress data show the similar trends and riser-to-riser variations as the apparent viscosity data. Average yield stress values vary by at most a factor of 2 among the FG-1 tanks.

\subsubsection{Tank Data Used in This Report}

At the time of this writing, data reconciliation studies have been completed for Tanks AN-103, AN-104, AN-105, and AW-101. The results of these studies will be used in the various analyses to evaluate different mitigation schemes. For Tank SY103, the data from Ref. 18 will be used.

Tank data used in this report are summarized in Table 3-7. If data are available from data reconciliation studies, they are used. If not, data from other sources are used. The source of each item of data is indicated in the table.

\subsection{Tank History and Status}

This section presents additional discussion on the history of each of the FG-1 tanks and on their current tank contents. Although quantitative results relating to void fractions, layer thicknesses, etc., have already been presented in earlier sections, this section includes a discussion of the waste chemical composition and observed gas release behavior. Numerical values quoted in the next sections are the results of data reconciliation studies and are given as best-estimated values without quantification of uncertainty.

\subsubsection{Tank AN-103}

Tank AN-103 began receiving waste in December 1982. The final fill occurred in January 1986, when $\sim 700,000$ gal. of waste from the 86-2 evaporator campaign was 
added. The current waste volume, including retained gas, is $\sim 955,000$ gal., and it is classified as double-shell slurry feed. ${ }^{9}$

The waste composition is typical of double-shell slurry feed consisting primarily of sodium hydroxide, sodium nitrate, sodium r.trite, sodium alumi:.ate, sodium carbonate, sodium sulphate, sodium phosphate, sodium salts of the organic complexant residue, and salts of alkaline earth and transition metals. The hydroxide concentration in the liquid is $5.8 \mathrm{~mole} / \mathrm{L}$, which is high compared to Tank SY-101. The TC??total organic carbon (TOC) concentration is 2 to $3 \mathrm{~g} / \mathrm{L}$, which is much lower than the TOC concentration in Tank SY-101. Cesium-137 is the dominant source of radiolytic heat generation. The total heat generation in Tank AN-103 is $\sim 32,000 \mathrm{Btu} / \mathrm{h}$.

The waste configuration is typical of other FG-1 tanks. The waste consists of three layers: a nonconvective layer, a convective layer, and a crust. The solid particles in the nonconvective layer consist primarily of sodium aluminate $(54 \mathrm{wt} \%)$. The other solid components are sodium carbonate (16 wt \%), sodium nitrite $(15 \mathrm{wt} \%)$, slightly soluble salts of alkaline earth and transition metals (11 wt \%), sodium sulphate $(2 \mathrm{wt} \%)$, and sodium oxalate ( $2 \mathrm{wt} \%)$.

After the final fill, the average waste temperature was recorded as $\sim 55^{\circ} \mathrm{C}$, which was significantly higher than the current value of $\sim 42^{\circ} \mathrm{C}$. The temperature profile data indicate that the nonconvective layer formed a thickness of $\sim 133$ in., which is less than the current value of $\sim 156$ in. The temperature profile also indicates that a crust $>24$ in. formed some after the tank was filled. Slurry growth was observed soon after the final fill. After the final fill, the solid particles in Tank AN-103 probably consisted of sodium aluminate, sodium carbonate, slightly soluble salts of alkaline earth and transition metals, sodium sulphate, and sodium oxalate. Cooling of the waste from $55^{\circ} \mathrm{C}$ to $42^{\circ} \mathrm{C}$ during the first 1 to $3 \mathrm{yr}$ caused precipitation of sodium nitrite and additional sodium aluminate. Gas accumulation accounts for $\sim 19$ in. of the $23 \mathrm{in}$. if the solids fraction in the nonconvective layer remained constant. In Tank AN-103, it appears that cooling caused the solids fraction in the nonconvective layer to increase, whereas the layer thickness remained nearly constant.

The nonconvective layer retains a significant amount of gas. The average gas fraction in the nonconvective layer is $\sim 10 \mathrm{vol} \%$ ?. The average bulk density of the nonconvective layer, including the retained gas, is approximately equal to the density of the nonconvective layer. The retained gas is $\sim 68$ mole $\% \mathrm{H}_{2}$. The waste level continues to increase at a very low rate, indicating that gas is still accumulating. No large GREs have been observed in Tank AN-103. The level data indicate that there have been no significant level drops in Tank AN-103. Temperature data do not show any evidence of mixing of the nonconvective layer. Only a single GRE has been detected by the SHMS, and this GRE was small. 
TABLE 3-7

SUMMARY OF TANK DATA USED IN ANALYSIS OF MITIGATION
STRATEGIESCLARIFY FOOTNOTES TO TABLE

\begin{tabular}{|c|c|c|c|c|c|c|}
\hline Parameter & AN-103 & $\mathrm{AN}-104$ & AN-105 & AW-101 & SY-103 & Comments \\
\hline Waste level (m) & 8.84 & 9.75 & 10.45 & 10.41 & 6.91 & $\begin{array}{l}\text { from data } \\
\text { reconciliation }\end{array}$ \\
\hline $\begin{array}{l}\text { Convective-layer } \\
\text { density }\left(\mathrm{kg} / \mathrm{m}^{3}\right)\end{array}$ & 1480 & 1430 & 1420 & 1400 & 1470 & $\begin{array}{l}\text { from data } \\
\text { reconciliation }\end{array}$ \\
\hline $\begin{array}{l}\text { Nonconvective-layer } \\
\text { density (gas-free) } \\
\left(\mathrm{kg} / \mathrm{m}^{3}\right)\end{array}$ & 1650 & 1590 & 1600 & 1610 & 1570 & $\begin{array}{l}\text { from data } \\
\text { reconciliation }\end{array}$ \\
\hline $\begin{array}{l}\text { Nonconvective-layer } \\
\text { void fraction (\%) }\end{array}$ & 10.1 & $\overline{5.4}$ & 3.2 & 3.6 & $\overline{6.4}$ & $\begin{array}{l}\text { from data } \\
\text { reconciliation } \\
\end{array}$ \\
\hline $\begin{array}{l}\text { Nonconvective-layer } \\
\text { void fraction (\% } \\
\text { volume) }\end{array}$ & 0.129 & 0.104 & 0.174 & 0.251 & 0.173 & $\begin{array}{l}\text { from data } \\
\text { reconciliation }\end{array}$ \\
\hline $\begin{array}{l}\text { Nonconvective-layer } \\
\text { thickness }(\mathrm{m})\end{array}$ & 4.04 & 4.05 & 4.27 & 3.11 & 3.34 & $\begin{array}{l}\text { from data } \\
\text { reconciliation } \\
\end{array}$ \\
\hline Crust thickness (m) & 0.66 & 0.38 & 0.15 & 0.61 & 0.2 & $\begin{array}{l}\text { from data } \\
\text { reconciliation }{ }^{\mathrm{a}} \\
\end{array}$ \\
\hline $\begin{array}{l}\text { Convective-layer } \\
\text { thickness }(\mathrm{m})\end{array}$ & 4.14 & $\overline{5.32}$ & 6.03 & 6.69 & 3.37 & $\begin{array}{l}\text { from data } \\
\text { reconciliation }{ }^{a} \\
\end{array}$ \\
\hline $\begin{array}{l}\text { Average nonconvective- } \\
\text { layer temperature }(\mathrm{K})\end{array}$ & 314.3 & 317.5 & 313.5 & 314.1 & 309.3 & See Sec. 3.2.4 \\
\hline $\begin{array}{l}\text { Average convective- } \\
\text { layer temperature (K) }\end{array}$ & 316 & 314 & 309.7 & 312.7 & 305.9 & See Sec. 3.2.4 \\
\hline $\begin{array}{l}\text { Average viscosity in } \\
\text { nonconvective layer } \\
(\mathrm{Pa}-\mathrm{s})\end{array}$ & 24600 & 10600 & 12900 & 15900 & 18200 & See Sec. 3.2 .5 \\
\hline $\begin{array}{l}\text { Average pressure in } \\
\text { nonconvective layer } \\
\text { (atm) }\end{array}$ & 1.97 & 2.08 & 2.17 & 2.22 & 1.69 & $\begin{array}{l}\text { from data } \\
\text { reconciliation }\end{array}$ \\
\hline $\begin{array}{l}\text { Total gas generation } \\
\text { rate in nonconvective } \\
\text { layer (scft/day) }\end{array}$ & 3.21 & 3.56 & 2.67 & 2.03 & 6.91 & $\begin{array}{l}\text { from data } \\
\text { reconciliation }^{\mathrm{a}}\end{array}$ \\
\hline $\begin{array}{l}\mathrm{H}_{2} \text { fraction in insoluble } \\
\text { retained gas in } \\
\text { nonconvective layer (\%) }\end{array}$ & 67.6 & 66.0 & 58.0 & 45.6 & 60.6 & $\begin{array}{l}\text { from data } \\
\text { reconciliation }\end{array}$ \\
\hline $\begin{array}{l}\mathrm{N}_{2} \mathrm{O} \text { fraction in } \\
\text { insoluble retained gas in } \\
\text { nonconvective layer }(\%)\end{array}$ & 3.2 & 9.8 & 10.6 & 2.1 & 12.8 & $\begin{array}{l}\text { from data } \\
\text { reconciliation }\end{array}$ \\
\hline $\begin{array}{l}\mathrm{N}_{2} \text { fraction in insoluble } \\
\text { retained gas in } \\
\text { nonconvective layer (\%) }\end{array}$ & 27.0 & 21.3 & 29.2 & 50.2 & 23.4 & $\begin{array}{l}\text { from data } \\
\text { reconciliation }^{a}\end{array}$ \\
\hline $\begin{array}{l}\mathrm{CH}_{4} \text { fraction in insoluble } \\
\text { retained gas in } \\
\text { nonconvective layer (\%) }\end{array}$ & 0.5 & 1.0 & 0.7 & $\overline{0.4}$ & 0.4 & $\begin{array}{l}\text { from data } \\
\text { reconciliation }^{\mathrm{a}}\end{array}$ \\
\hline $\begin{array}{l}\text { Maximum releasable } \\
\text { dissolved } \mathrm{H}_{2} \text { (scft) }\end{array}$ & 72 & 2241 & 163 & 908 & $\overline{0^{+}}$ & $\begin{array}{l}\text { from data } \\
\text { reconciliation }{ }^{\mathrm{a}} \\
\end{array}$ \\
\hline
\end{tabular}


TABLE 3-7 (cont)

\section{SUMMARY OF TANK DATA USED IN ANALYSIS OF MITIGATION STRATEGIESCLARIFY FOOTNOTES TO TABLE}

\begin{tabular}{|c|c|c|c|c|c|c|}
\hline P-rameter & AN-103 & AN-104 & AN-105 & $A W-101$ & SY-103 & Comments \\
\hline $\begin{array}{l}\text { Maximum releasable } \\
\text { dissolved } \mathrm{NH}_{3} \text { (scft) }\end{array}$ & 1339 & 22 & 644 & 6 & $340^{* *}$ & $\begin{array}{l}\text { from data } \\
\text { reconciliation }^{\text {a }}\end{array}$ \\
\hline $\begin{array}{l}\text { Maximum releasable } \\
\text { other dissolved gases } \\
\text { (scft) }\end{array}$ & 102 & 1136 & 763 & 1077 & $0^{+}$ & $\begin{array}{l}\text { from data } \\
\text { reconciliation }\end{array}$ \\
\hline Dome volume $\left(\mathrm{ft}^{3}\right)$ & 60734 & 47602 & 37331 & 37920 & 88708 & $\begin{array}{l}\text { determined using: } \\
\text { volume }= \\
35343+4418^{\mathrm{a}}(34.75- \\
\text { level in feet) }\end{array}$ \\
\hline $\begin{array}{l}\text { Hydrogen generation } \\
\text { rate in nonconvective } \\
\text { layer (scft/day) }\end{array}$ & 2.17 & 2.35 & 1.54 & 0.93 & 4.19 & $\begin{array}{l}\text { determined from } \\
\text { total gas generation } \\
\text { rate and } \mathrm{H}_{2} \\
\text { composition (data } \\
\text { reconciliation) }\end{array}$ \\
\hline $\begin{array}{l}\text { Heat load in } \\
\text { nonconvective layer }(W)\end{array}$ & 4475 & 4962 & 6389 & 4625 & & $\begin{array}{l}\text { Determined using } \\
\text { formula: Heat load } \\
\text { in Watts = } \\
0.00593^{\mathrm{a}}(0.8338 \mathrm{Cs} \\
(\mathrm{Ci})+1.1 \mathrm{Sr}(\mathrm{Ci})) \text {, } \\
\text { where } \mathrm{Ci} \text { of } \mathrm{Cs} \text { and } \\
\text { Sr are obtained from } \\
\text { data reconciliation }{ }^{c}\end{array}$ \\
\hline $\begin{array}{l}\text { Heat load in convective } \\
\text { layer (W) }\end{array}$ & 4332 & 5165 & 5174 & 7191 & & Same as above \\
\hline Heat load in crust (W) & 667 & 371 & 137 & 754 & & Same as above \\
\hline
\end{tabular}

${ }^{a}$ Tank SY-103 values are from Ref.18.

${ }^{b}$ Releasable ammonia volume in Tank SY-103 is based on the assumptionof a $6 \% \mathrm{NH}_{3}$ fraction in the release gas.

Assuming that ammonia is the only dissolved gas in Tank SY-103.

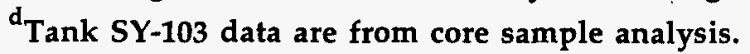

Tank AN-103 is unique among the FG-1 tanks because no significant GREs have occurred, although it retains a large volume of gas. The history of this waste may explain this behavior. After the final fill, the solids settled, producing a layer slurry layer?? with a yield stress between 50 and $200 \mathrm{~Pa}$, which is typical of other FG-1 tanks. Salts that precipitated out of the liquid as a result of cooling increased in solids fraction in the nonconvective layer, which in turn resulted in an increase in slurry density and strength. Increased density and strength favor increased gas retention. Increased slurry strength also inhibits mixing of the nonconvective layer. 


\subsubsection{Tank AN-104}

Additions to Tank AN-104 began in December 1982 with waste from the 83-1 and 83-2 evaporator campaigns. After a series of transfers, the inventory was reduced to 140,00 ? gal. in September 1094. In November 1984, 790,000 gal. of waste was added during the 84-5 evaporator campaign. Finally 120,000 gal. was added in April 1985 during the 85-3 evaporator campaign. The current waste volume, including retained gas, is $\sim 1,050,000$ gal., and it is classified as double-shell slurry feed. ${ }^{9}$

The waste consists primarily of sodium hydroxide, sodium nitrate, sodium nitrite, sodium aluminate, sodium carbonate, sodium sulphate, sodium phosphate, sodium salts of the organic complexant residue, salts of alkaline earth and transition metals, which is typical of double-shell slurry feed. The hydroxide concentration in the liquid is $\sim 4 \mathrm{~mole} / \mathrm{L}$, which is high compared to Tank SY-101. The TOC concentration is $\sim 3 \mathrm{~g} / \mathrm{L}$, which is much lower than the TOC concentration in Tank SY-101. Cesium-137 is the dominant source of radiolytic heat generation. The total heat generation in Tank AN-103 is $\sim 36,000 \mathrm{Btu} / \mathrm{h}$.

The waste consists of three layers: a nonconvective layer, a convective layer, and a crust; this is typical of other FG-1 tanks. The solid particles in the nonconvective layer consists primarily of sodium carbonate $(48 \mathrm{wt} \%)$. The other solid components are slightly soluble salts of alkaline earth and transition metals $(29 \mathrm{wt} \%)$, sodium sulphate $(18 \mathrm{wt} \%)$, and sodium oxalate $(5 \mathrm{wt} \%)$. No solids precipitated from the convective-layer samples when they were cooled to ambient temperature, indicating that the liquid is not saturated with sodium nitrate, sodium nitrite, or sodium aluminate.

After the final fill, the average waste temperature was $\sim 43^{\circ} \mathrm{C}$, which is only slightly higher than the current average waste temperature of $\sim 40^{\circ} \mathrm{C}$. The nonconvectivelayer thickness after the final fill was $\sim 148$ in. Gas accumulation accounts for the difference between the initial nonconvective-layer thickness and the current value of 159 in. Because of the lack of a significant temperature change and because the solids inventory in Tank AN-105 is not sensitive to temperature, the nonconvective layer has not changed significantly since the initial fill.

The nonconvective layer retains gas. The average gas fraction in the nonconvective layer is $\sim 5.4$ vol. $\%$. The retained gas is 66 mole $\% \mathrm{H}_{2}$. Small GREs occur in Tank AN-104. The maximum observed hydrogen concentration in the dome was $\sim 5900 \mathrm{ppm}$, and the maximum observed level drop was $2.7 \mathrm{in}$. The level drops are small compared to the 5- to 13-in. level drops observed in Tank SY-101. Because of the noise in the level measurement, GREs in Tank AN-104 cannot be identified solely on the basis of level data. Temperature profile data indicate that a portion of the nonconvective layer mixes with the convective layer during a GRE. A thermal balance calculation indicates that $\sim 5 \%$ of the nonconvective layer participates in GREs. 


\subsubsection{Tank AN-105}

Additions to Tank AN-105 began in late 1982. Significant transfers to and from this tank occurred between 1981 and 1985. The waste inventory was removed in April 1985. The last major fil! occurred in April 1985 during the 85-3 evaporator campaign, when $\sim 1,130,000$ gal. of waste was added to a nearly empty tank. The current waste is classified as double-shell slurry feed (Ref. 9).

The waste composition is typical of double-shell slurry feed, consisting primarily of sodium hydroxide, sodium nitrate, sodium nitrite, sodium aluminate, sodium carbonate, sodium sulphate, sodium phosphate, sodium salts of the organic complexant residue, and salts of alkaline earth and transition metals. The hydroxide concentration in the liquid is $\sim 3.3 \mathrm{~mole} / \mathrm{L}$, which is slightly higher than the liquid in Tank SY-101. The TOC concentration is $\sim 3 \mathrm{~g} / \mathrm{L}$, which is much lower than the TOC concentration in Tank SY-101. Cesium-137 is the dominant source of radiolytic heat generation. The total heat generation in Tank AN-103 is $\sim 40,000$ $\mathrm{Btu} / \mathrm{h}$.

The waste consists of three layers: a nonconvective layer, a convective layer, and a crust; this is typical of other FG-1 tanks. The solid particles in the nonconvective layer consists primarily of sodium carbonate $(70 \mathrm{wt} \%)$. The other solid components are slightly soluble salts of alkaline earth and transition metals (14 wt \%), sodium oxalate (9 wt \%), and sodium sulphate (7 wt \%). No solids precipitated from the convective-layer samples when they were cooled to ambient temperature, which indicates that the liquid is not saturated with sodium nitrate, sodium nitrite, or sodium aluminate.

After the final fill, the average waste temperature was $\sim 42^{\circ} \mathrm{C}$, which is only slightly higher than the current average waste temperature of $\sim 37^{\circ} \mathrm{C}$. The nonconvectivelayer thickness after the final fill was $\sim 157$ in. Gas accumulation and measurement uncertainty account for the difference between the initial nonconvective-layer thickness and the current value of $\sim 168$ in. Because of the lack of a significant temperature change and because the solids inventory in Tank AN-105 is not sensitive to temperature, the nonconvective layer has not changed significantly since the initial fill.

The nonconvective layer retains gas and has an average gas fraction of $\sim 3.2 \mathrm{vol} \%$. The retained gas is 57 mole $\% \mathrm{H}_{2}$. Small GREs occur in Tank AN-105. The maximum observed hydrogen concentration in the dome was $\sim 17,000 \mathrm{ppm}$, and the maximum observe level drop was $2.5 \mathrm{in}$. The level drops are small compared to the 5- to 13-in. level drops observed in Tank SY-101. Temperature profile data indicate that a portion of the nonconvective layer mixes with the convective layer during a GRE. Thermal balance calculations indicate that $\sim 25 \%$ of the nonconvective layer participates in GREs. 


\subsubsection{Tank AW-101}

Additions to Tank AW-101 began in late 1981. Significant transfers to and from this tank occurred between 1981 and 1986. The last major fill occurred in mid-1986, when 1,100,000 gal. of waste from the 86-5 eraporator campaign was added to a nearly empty tank. The waste is classified as double-shell slurry feed (Ref. 9).

The waste consists primarily of sodium hydroxide, sodium nitrate, sodium nitrite, sodium aluminate, sodium carbonate, sodium sulphate, sodium phosphate, sodium salts of the organic complexant residue, and salts of alkaline earth and transition metals, which is typical of double-shell slurry feed. The hydroxide concentration in the liquid is 5.0 mole/L, which is high compared to Tank SY-101. The TOC concentration is $\sim 4 \mathrm{~g} / \mathrm{L}$, which is much lower than the TOC concentration in Tank SY-101. Cesium-137 is the dominant source of radiolytic heat generation. The total heat generation in Tank AN-103 is $\sim 43,000 \mathrm{Btu} / \mathrm{h}$.

The waste consists of three layers: a nonconvective layer, a convective layer, and a crust; this is typical of other FG-1 tanks. The solid particles in the nonconvective layer consists primarily of sodium carbonate $(87 \mathrm{wt} \%)$. The other solid components are sodium carbonate $(10 \mathrm{wt} \%)$, sodium sulphate $(1 \mathrm{wt} \%)$, sodium oxalate $(1 \mathrm{wt} \%)$, and slightly soluble salts of alkaline earth and transition metals $(<1 \mathrm{wt} \%)$. The nonconvective-layer thickness is currently 122 in., and the crust thickness is 24 in.

After the final fill in 1986 , the average vaste temperature was $\sim 51^{\circ} \mathrm{C}$, which is significantly greater than the current waste temperature of $\sim 38^{\circ} \mathrm{C}$. As the waste cooled, the nonconvective-layer thickness increased significantly. In 1986, the nonconvective-layer thickness was $~ 96$ in., which is much less than the current value of $\sim 122 \mathrm{in}$. The nonconvective-layer growth is the result of precipitation of sodium nitrate as the waste cooled. Gas accumulation can account for only $\sim 4$ in. of this growth. The major difference in the solids in 1986 and the solids currently in the tank is that there was less sodium nitrate in 1986.

The nonconvective layer retains some gas and has an average gas fraction of $\sim 3.6 \mathrm{vol} \%$. Based on the level data, the gas fraction in Tank AW-101 appears to have obtained a steady-state value. Gas migrates out of the nonconvective layer at the rate it is generated. Data from the RGS indicate that the gas trapped in the nonconvective layer is $\sim 46$ mole $\% \mathrm{H}_{2}$. Some of the nitrogen from the air entrained in the waste when the tank was filled may still be trapped in the nonconvective layer. Because the rate at which gas migrates out of the nonconvective layer is low and because the total gas fraction is low, the nitrogen from the entrained air may constitute a significant fraction of the retained gas. Therefore, the gas generated by the waste may not have the same composition as the gas retained in the waste. We estimate that the gas generated in Tank AW-101 is $\sim 65$ mole $\% \mathrm{H}_{2}$. As time progresses, we expect that the retained gas in Tank AW-101 will become richer in hydrogen. 
Only small GREs have been observed in Tank AW-101. Between October 1994 and March 1996, small, frequent GREs were detected with the SHMS. No changes in the temperature profile were observed during these GREs, indicating that no mixing occurs in the nonconvective layer. There is no correlation between the level drop and gas release volume. A level drop was observed for only 1.alf of the GREs between October 1994 and March 1996. Although the amount of hydrogen dissolved in the waste is small, we believe that the release of dissolved hydrogen from the convective layer is a significant factor in the small GREsthat they resulted or that they were small? observed in Tank AW-101, and it explains the lack of correlation between the level drop and gas release volume.

\subsubsection{Tank SY-103}

Additions to Tank SY-103 began in 1977. In late 1980, the complexant concentration waste in the tank was pumped down to a heel. At this time, $\sim 360,000$ gal. of doubleshell slurry was added to the tank. Since January 1981, there have been two major additions to Tank SY-103. In mid-1985, 70,000 gal. of uranium ion exchange waste was transferred to Tank SY-103, and in mid-1988, 130,000 gal. of supernatant liquid and water was transferred from Tank SX-104. The tank Tank SY-103 currently contains $\sim 744,000$ gal. of waste, and it is classified as complexant concentrate.

The waste consists primarily of sodium hydroxide, sodium nitrate, sodium nitrite, sodium aluminate, sodium carbonate, sodium sulphate, sodium phosphate, sodium salts of the organic complexant residue, and salts of alkaline edrth and transition metals, which is typical of double-shell slurry feed. The hydroxide concentration in the liquid is $\sim 1.7$ moles/ $\mathrm{L}$, which is less than the hydroxide concentration in Tank SY-101. The hydroxide concentration in the Tank SY-101 liquid is $\sim 2.6 \mathrm{~mole} / \mathrm{L}$. The TOC in the liquid is $\sim 10$ mole $/ \mathrm{L}$, which is lower than the $\sim 17 \mathrm{~g} / \mathrm{L}$ in the Tank SY-101 liquid, but much greater than the $\sim 3 \mathrm{~g} / \mathrm{L}$ found in the liquid of other FG-1 tanks. Cesium-137 is the dominant source of radiolytic heat generation. The total heat generation in Tank SY-103 is $\sim 21,000 \mathrm{Btu} / \mathrm{h}$.

The waste consists of three layers: a nonconvective layer, a convective layer, and a crust; this is typical of other FG-1 tanks. The solid particles in the nonconvective layer consist of sodium nitrate $(\sim 36 \mathrm{wt} \%)$, sodium carbonate $(\sim 21 \mathrm{wt} \%)$, sodium aluminate $(\sim 18 \mathrm{wt} \%)$, slightly soluble salts of alkaline earth and transition metals $(\sim 12 \mathrm{wt} \%)$, sodium oxalate $(\sim 9 \mathrm{wt} \%)$, and sodium sulphate $(\sim 3 \mathrm{wt} \%)$. There is uncertainty as to whether the solid phase of aluminum is sodium aluminate or aluminum hydroxide. The low hydroxide concentration in the waste may favor aluminum hydroxide.

After the 1985 addition, the average waste temperature was $\sim 48^{\circ} \mathrm{C}$, and the nonconvective layer was 146 in. thick. For several years after the 1988 addition, there are no temperature data; thus, it is impossible to determine what happened to the nonconvective layer as a result of that addition. The average waste temperature in 1991 was $\sim 46^{\circ} \mathrm{C}$. The current waste temperature is $\sim 33^{\circ} \mathrm{C}$; thus, the waste has cooled significantly. The current nonconvective-layer thickness is $\sim 133$ in., which is 
less than the thickness in 1985. The decrease in the nonconvective-layer thickness indicates that the 1988 addition may have had dissolved solids.

The nonconvective layer retains gas and has an average gas fraction in Tank SY-103 of $6.2 \mathrm{rol} \%$. The average bulk density of the nonconvective layer, including the retained gas, is nearly equal to the convective-layer density. We estimate that the retained gas is $\sim 34$ mole $\% \mathrm{H}_{2}$. The gas composition is much more similar to the gas in Tank SY-101 than it is to the other FG-1 tanks that contain double-shell slurry feed. We believe that the high TOC concentration in the liquid in Tanks SY-101 and SY-103 accounts for the difference.

Small GREs have been observed in Tank SY-103. The maximum hydrogen concentration measured in the dome space during a GRE was $\sim 3000 \mathrm{ppm}$, and the maximum observed level drop was 1.9 in. There is a moderate degree of correlation between the peak hydrogen concentration and level drop. The lack of a good correlation can be accounted for by a \pm 0.6 in. uncertainty in level measurement. Temperature profile data indicate that a portion of the nonconvective layer mixes with the convective layer during a GRE. 


\section{METHODOLOGY AND PROCESS OF EVALUATION OF MITIGATION STRATEGIES}

An approach similar to that used in Ref. 2 was adapted as the methodology for this study. Four members of the Hanford Waste Tank Safety team of the Nuclear Systems Analysis and Design Group at LANL formed a small team. The team members, C. Unal, W. Kubic, J. R. White, and P. Sadasivan, are familiar with the Hanford waste tanks and have been involved with various Hanford-related safety studies done at LANL over the last 5 years. They have been involved with the various aspects of the FG project and have backgrounds in different disciplines. It is believed that the team members have the necessary qualifications to perform the evaluation. The team was limited to four staff members mainly because of limited funding and time.

The mitigation strategies or concepts have been reidentified. The team reviewed Refs. 2 and 3 . The first team meeting was held to review the findings of each team member and develop a list of possible mitigation strategies. A total of 37 mitigation strategies/concepts were generated. This new list included 23 concepts proposed in Ref. 2 and 14 new concepts. As noted earlier, the FG hazard comprises issues relating to gas generation, gas retention, gas release, and the possibility of subsequent ignition in the dome space. Different mitigation concepts identified in this study attempt to mitigate the problem by focusing on one or more of the individual components of the FG hazard. Each concept is discussed briefly in Section 6.

The evaluation methodology determined 14 judgment factors to be used in the ranking method:

1. sound principle,

2. proof of principle,

3. new data,

4. new analysis,

5. technology status,

6. preclude retrieval,

7. cost,

8. schedule,

9. implementation hazard,

10. open safety issues,

11. applicability to FG-1 DSTs,

12. passive vs active concepts,

13. compatibility for combined concepts, and

14. general applicability.

The ranking method involved two steps. In the first step, concepts were ranked based on the first six judgment factors listed above-that is, importance was given to factors such as soundness of principle and availability of new data and analysis tools. 
The applicability of new data and analysis tools for a better reevaluation of a mitigation strategy also was considered to be key criteria.

Some of the mitigation concepts are still at conceptual stage, and there are no detailed engineering plans for design and processes. The evaluation of cost, schedule, and detailed analysis of safety hazards would not be very meaningful for purely conceptual strategies. Therefore, effects of cost and schedule are considered in the second step of the ranking process. This approach was taken to ensure that mitigation concepts that are based on unproven or uncertain principles, yet are relatively inexpensive and quick to implement, were eliminated from consideration early in the process; scarce resources were not spent on analyzing such schemes.

All 37 mitigation strategies were ranked from 0 to 4 using the first six judgment factors listed in Section 4 . Zero meant the least favorable, whereas 4 meant the most favorable. The ranking process is discussed further in Sec. 7.

The leading candidates for mitigation concepts identified by the two-step ranking process were analyzed to quantify the effect of the mitigation concepts on the FG hazard (gas generation, retention, and release). Necessary analyses required for this purpose were identified. The main analysis tools available at LANL include the material balance calculations developed for data reconciliation studies of FG-1 tanks (Ref. 20), the transient void model (Ref. 21), and various closed-form solutions developed for safety assessment studies (Refs. 22 and 23). These tools were used to estimate the state of the waste (solid fraction, gas void fraction and other parameters pertinent to gas generation, retention, and release) before and after the implementation of a mitigation strategy to FG-1 tanks. The details of these analyses are provided in Sec. 8.

The implementation hazards were not evaluated in detail. The quantification efforts are based on best-estimate methodology, data, and our engineering judgments. No attempt was made to estimate the uncertainty in the analysis efforts. The quantification given in this report reflects our opinion/prediction based on our current understanding and knowledge of the waste stored in FG-1 DSTs. 


\section{ANALYSIS FRAMEWORK}

As stated in the introduction, the FG safety issue is related to the possibility that a sufficiently large GRE could cause FG concentrations to exceed flammable limits and be ignited in the presence of sufficient oxidizer Thus, to initiate an ignition in the dome space, three elements must occur be present concurrently:

1. flammable concentrations of fuel,

2. a sufficient quantity of oxidizer, and

3. an ignition source.

The mitigation or elimination of one of these three elements mitigates the FG hazard. The mitigation strategies should be classified according to the particular element (or elements) they address.

Mitigation concepts aimed at eliminating or reducing the concentration of fuel in the dome space could do so by

- reducing the generation of the FGs in the waste, the main components being hydrogen and ammonia;

- reducing the retention of these gases in the waste so that gases are released in a more continuous manner, which can be managed safely using an appropriate ventilation system; or .

- diluting the dome space concentrations by increasing the dome volume.

The oxidizer comprises oxygen present in the air and nitrous oxide generated in the waste. Mitigation concepts aimed at eliminating or reducing the amount of oxidizer in the dome space could minimize the amount of nitrous oxide generated in the waste itself or reduce the concentration of oxygen in the dome space. Also, it is possible to have flammable fuel (hydrogen and ammonia) and oxidizer in the waste itself before the FG is released into the dome space. Air is in the tank dome space and sometimes is introduced into the waste in small amounts. Mitigation concepts may be developed to eliminate the oxidizer (air and nitrous oxide) in the waste or tank dome space.

The mitigation concepts are identified in Sec. 6. They are classified based on their ability to affect the following parameters or mechanisms:

- the gas release volume,

- the gas inventory or retention,

- the gas generation rate,

- the dome volume,

- the amount of oxidizer, and

- the ignition source. 
Among the above mechanisms, the issues of gas generation, retention, and release are somewhat interrelated. The mechanisms preventing the ignition source are relatively independent from the others. The processes of gas generation, retention, and release occur in different ways and by different mechanisms in waste tanks; thus, a good understanding of these processes is necessary to de. elop a means to mitigate them. In the last 4 years, significant progress has been made in developing a knowledge base attempting to explain the physics of gas generation, retention, and release. However, because of the very complex nature of these processes, much remains uncertain.

A detailed discussion of the current knowledge and understanding of the mechanisms of gas generation, retention, and release is outside the scope of this report. The current state of the art on this subject is well summarized in Refs. 1 and 24. This report is prepared primarily in support of the expert elicitation methodology being developed in an attempt to close the FG USQ. 


\section{IDENTIFICATION OF MITIGATION STRATEGIES}

This section develops a comprehensive list of mitigation strategies. The framework used to identify different strategies has been discussed in Sec. 5 .

\subsection{Mitigation Strategies}

A total of 37 mitigation strategies were generated:

1. pump mixing (horizontal jet mixing),

2. vertical jet mixing,

3. nonconvective-layer recirculation,

4. past practice sluicing,

5. mechanical stirring,

6. water lancing of the nonconvective layer,

7. air lancing of the nonconvective layer,

8. steam lancing of the nonconvective layer,

9. nitrogen lancing of the nonconvective layer,

10. nitrogen sparging,

11. inerting dome space,

12. supernatant liquid removal,

13. heating,

14. heat briefly to atmospheric boiling point,

15. organic destruction by heating,

16. organic destruction by chemical means,

17. dilution,

18. high-frequency sonic agitation,

19. low-frequency sonic agitation,

20. spark control,

21. surfactant addition to modify slurry rheology,

22. surfactant addition to reduce bubble attachment,

23. removal of organic complexants by supercritical extraction,

24. removal of radioactive isotopes,

25 . separation of high -molecular-weight components by ultrafitration,

26. solvent extraction of select chemical species,

27. removal of aluminate,

28. removal of sodium carbonate,

29. addition of mineral-forming agents,

30 . lowering $\mathrm{pH}$ of the waste,

31 . hydroxide addition,

32. cooling the waste,

33. addition of free-radical scavenger,

34. retrieval,

35. solidification of waste,

36. mitigation of burn (MPRs), and

37. dome explosion suppression. 


\subsubsection{Pump Mixing (Horizontal Jet Mixing)}

The principle of the mitigation concept is to mix the tank contents (nonconvective layer with convective-layer supernatant) by using a submerged liquid jet pump. Mixirg the nonconvective layer with the convective layer is expected to impart energy to disrupt the nonconvective-layer region through the reduction of shear strength and apparent viscosity of the nonconvective layer. Successful mixing prevents settling of solid salt particles so that a nonconvective layer with shear strength enough to overcome the buoyancy of FG bubbles can be prevented. The rate of settling of salt particles is slow. Complete settling takes $\sim 3$ to 8 weeks. Thus, intermittent mixing may be sufficient to prevent the formation of a nonconvective. layer; continuous mixing may not be necessary.

The most important effect of pump mixing is the reduction of the solid fraction through the resuspension of solids. This in turn reduces the waste strength and apparent viscosity. The net effect is that gas retention in the nonconvective layer is reduced. Pump mixing does not affect the gas generation directly. However, using a powerful submerged mixer pump would heat the waste when used continuously. Higher waste temperatures cause higher gas generation rates. The heating effect is not expected to be a major problem if pump operations are limited to short durations. Pump mixing resuspends a portion of the nonconvective layer, and thus, possible crystal ripening or gel formation is decreased.

Efiiciency of mixing is a strong function of the fluid dynamical properties of the convective and nonconvective layers and the characteristics of the jet pump (flow rate, nozzle size, power, etc.). New data on the properties of FG-1 tanks (shear strength, viscosity and void fraction) are available for reassessment of the effects of this mitigation scheme.

The pump mixing concept has been demonstrated in Tank SY-101, with the successful implementation and operation of the mixer pump. The pump is operated at constant speeds during 15-min intervals three times per week. This operation maintains a constant waste level of $\sim 400 \mathrm{in.}$ Episodic gas releases have been eliminated; the FG is released more often and in smaller amounts. The FG concentrations in the tank dome space were less than $25 \%$ of the LFL, and the tank dome space was not pressurized during pump operations.

The consolidation or redistribution of solids during pump mixing is a concern. Some regions at the bottom of the tank and around the vertical walls may be undisturbed. No data are available to assess the zone of influence of the horizontal jet (region disturbed by the jet). In the vicinity of undisturbed regions, consolidation of salt as well as other heavy radionuclides can occur. As a result, the gas retention may be enhanced in these regions. The homogeneity of mixing is also a concern in the mixed layer. The differences in the thickness of the convective and nonconvective layers among the FG-1 tanks would require a different pump nozzle height in different tanks. The nozzle height also would affect the future use of the 
pump for retrieval purposes. The availability of risers for pump installation may be a problem for some tanks.

Pump failure is a risk that must be considered in the evaluation. The frequency of the gas release is functior of availability of thr spare pumps and their fabrication schedule. Pump life, surveillance, and maintenance are expensive and complex?not simple. The equipment is heavy and increases the dome loading significantly. It the eqpt?may require sluicing before installation of the pump. Decontamination of the pump during removal is not easy. The nozzle plugging is a practical problem.

Numerical simulations are available, but the benchmarking and validation of results are not demonstrated with confidence levels high enough to consider tools for extrapolation purposes. Preinstallation sluicing and installation of the pump can cause a gas release in the tanks. This is especially important if the tank void fraction is close to the predicted neutral buoyancy point. A time window in which the pump can be installed safely is necessary. The installation risk is high if a tank does not experience episodic releases that would allow a time window.

This concept has an advantage for disposal/retrieval/dilution activities. It can homogenize the waste for characterization and provide a method of mixing. The technology is already developed, proven, and in use. A safety assessment for this concept. It is easy to extend the existing safety assessment to other FG-1 tanks. The cost of the implementaition of this concept is high ( $\$ 10$ to $15 \mathrm{M})$, with a schedule of $\sim 46$ weeks.

\subsubsection{Vertical Jet Mixing}

This concept is similar to the previous horizontal jet mixing concept. The difference is the orientation of the jet. There is only one jet oriented toward the bottom of the tank in the vertical jet mixing. The downward single jet provides a higher -velocity region at the bottom of the tank in the form of a radial-flowing sheet of fluid. The mitigative features of this concept are almost identical to those of the horizontal pump mixing concept discussed in Sec. 6.1.1, although the shape of the zone of influence is different.

The motor can be mounted outside the tank, allowing easy maintenance and surveillance. The existing safety assessment for the horizontal jet mixer pump can be adapted easily for this option. Engineering and development are not available but are achievable in a reasonable amount of time.

A demonstration in a scaled tank may be necessary. The possibility of penetration of the bottom of the tank is an additional safety hazard. There is no direct analytical or experimental proof of principle, but the concept is very likely to work based on the experience of the horizontal jet mixer pump in Tank SY-101. The fabrication time and cost are similar to that of the horizontal pump. 


\subsubsection{Nonconvective Layer Recirculation}

This concept considers methods to recirculate the nonconvective layer with relatively low velocities to promote constant evolution of FG. The mitigative features of this concept are similar to those of the pump mixing corsepts discussed in Secs. 6.1.1 and 6.1.2. The efficiency of mixingrecirculation? is less than that in pump mixing because much lower energy is imparted to the fluid in this case. Examples of implementation methods of this concept are gas-lift circulators and liquid pistons.

The principle of the gas-lift circulator is to drive air through a distributor placed in the nonconvective and convective layers. Circulation through the distributor is achieved by the buoyancy of rising air bubbles. Distributors may have to be mounted on more than one riser to provide uniform mixing.

The principle of the liquid piston is to use pneumatic pressure to drive the fluids from convective and nonconvective layers from a reservoir out through an orifice into the nonconvective layer. When pressure is removed, liquid reenters the reservoir and the cycle is repeated. The jet created by the pressure pulse behaves as a periodic submerged jet. This device is basically a liquid-filled cylinder installed vertically in the tank, with nozzles at the lower end and a source of compressed gas at the upper end. Further details can be found in Ref. 2.

The liquid piston is an intrinsically safe ccncept from the standpoint of ignition hazards: the piston requires less maintenance, decontamination is relatively easy, the waste heating relative to horizontal jet mixing concept is less, and the method is simple and reliable.

Although the concepts are simple in principle, it is not clear that they would work as described. The injected air may remain in the waste, causing an increase in the rate of waste level rise and gas inventory. This would result in an increase in the frequency of natural episodic releases.

The liquid piston involves periodic agitation. The mixed waste may penetrate back into the liquid reservoir when the pressure is released. The FG can accumulate in the liquid reservoir, as it does in core sampling devices. The pressurization systems may need to be spark-free; otherwise, FG may be ignited in tubes, resulting in detonation. Air is introduced into the waste. The effect of the introduction of oxygen needs to be identified. The liquid piston concept has been proven for smaller tanks, but no description for the waste simulant or tests has been found.

There is no safety assessment for these concepts, and the cost is unknown. However, these concepts should be less expensive than the cost of the mixer pump concept. Technology is available and development efforts are minimal. 


\subsubsection{Past Practice Sluicing}

This concept is a new idea and was not considered by the previous review group. The principle of the concept is to sluice the nonconvective layer with the convective layer in the following fashion. The convective layer first is transfermed into another available tank, then a second pump is used to inject this liquid back into the nonconvective layer of the tank. This causes local mixing and agitation in the nonconvective layer, thus releasing retained gas locally. Mitigative features such as a reduction of solids fraction, waste strength, and viscosity, which are typical of pump mixing concepts, are applicable here also, but in a localized manner.

The sluice injection nozzle is designed so that it can be aimed at different areas of the nonconvective layer. In this way, the whole cross section of the tank can be swept in a series of successive sluicing operations. This technique is being used in the $\mathrm{W}-320$ sluicing project. The continuous use of the local jet would release gas in a safe and controlled fashion.

One drawback of this method is that it involves the transfer of some liquid out of the tank into a receiver tank, and thus has implications on tank space projections. In addition, the volume of the convective layer (the supernatant liquid) available for sluicing is a consideration; in some tanks, there may not be enough liquid available to mobilize the entire nonconvective layer.

The major disadvantage of the concept is that it only helps to relcase the gas, it does not prevent retention. Once the convective layer is consumed, the settling will cause re-formation of nonconvective layer. Therefore, the concept may have to be used periodically after the formation of a new nonconvective layer to prevent gas retention. On the other hand, depending on the waste composition of the two tanks, some of the sludge may be dissolved by the supernate from the receiver tank, thereby permanently affecting the gas retention characteristics. For purposes of mitigation, it is highly likely that if the waste were periodically pumped from one tank to another, the amount of retained gas could be maintained at a suitably low value.

As noted earlier, this concept is being used in Project W-320, so the technology is already in use at the site. The cost should be considered less than the cost of mixer pump. The need for repeated use of the concept increases the cost.

\subsubsection{Mechanical Stirring}

The principle of this concept is to resuspend the solids in the nonconvective layer by gentle stirring. The resuspension of solids is postulated to cause bubbles attached to solids to be freed. Stirring also may eliminate the formation of a solid matrix, therefore bubble trapment or gel formationtrapping bubbles or forming gel?. During stirring, bubbles may coalesce and become large enough to rise. Rising large bubbles also may entrain smaller bubbles. 
The proposed design consists of a rake that turns about a central axis. The arms of the rake extend outward toward the sides of the tank, thus increasing the swept area. This design is at the purely conceptual stage; engineering, development, testing, safety documentation, and fabrication are needed. There are no data on the effect of stirrir.g on shear strength, viscosity, settling velocity, and fluid properties. The system has rotating parts, and implementation may be a problem. The cost depends on the development efforts. The cost is unknown but is expected to be high.

\subsubsection{Water Lancing of the Nonconvective Layer}

This concept was not considered in Ref. 2. Water lancing has been performed for various reasons. Adding water dissolves solids and releases gas. This effect has been observed in Tank SY-101 when a 42-in.-diam lance was used before installation of the mixer pump. The idea of releasing gas by adding water can be applied to control the gas release rate and retention. Periodic use of the water lance at different locations in the waste would help to release gas periodically and prevent the nonconvective layer from approaching neutral buoyancy conditions. Thus, large episodic releases would be prevented.

Water lancing was used in Tank SY-101 between 1984 and 1986, and episodic gas releases were eliminated for 15 months. However, the waste level data indicated that the gas inventory has not been reduced. In Tank SY-101, two small GREs occurred during water lancing; however, better procedures may eliminate all GREs.

This technique is simple, and the safety concerns are known. Water lancing is a locally waste-intrusive activity. A safety assessment, which has been written for a similar activity, could be adapted for this activity relatively easily. The equipment is simplein what way? and available at the site. Several lances may be needed for uniform water addition.

Also, successive water additions would increase the level in the tanks, and thus, this method would not be applicable for tanks that already are close to the operating limits for the waste level. The amount of water that can be added to tanks is limited by the available dome space volume. In the long term, increasing the waste level may produce adverse effects. When water addition ceases because operating limits are reached, the nonconvective layer could reach neutral buoyancy again. The static pressure will be more than what it was before water addition. This will cause the volume of the episodic release to be a larger release volume at the same void fractions. The excess water may be needed to be transferred. A high convectivelayer thickness may alter heat losses and therefore the temperature of the tank. This concept may be a temporary solution to the FG hazard.

The effect of the concept on the gas generation, retention, and release can be estimated with the use of improved solubility models. The effects on shear strength and viscosity are difficult to estimate. Therefore, an estimation of solid fractions would give only qualitative trends on the amount of retention. 
The risk of implementation is low for this concept. Maintenance, operability, and decontamination are relatively easy. Fabrication and implementation of the concept are expected to be relatively fast.

\subsubsection{Air Lancing of the Nonconvective Layer}

This concept is similar to the previous one, and it was not considered in Ref. 2. Air lancing also was used in Tank SY-101 between 1986 and 1989. The principle of lancing with air or nitrogen is to induce local mixing or agitation, which causes gas release. The air is introduced (with a specified rate and time period) through a simple pipe inserted into nonconvective layer.

Past experience with air addition in Tank SY-101 can be used to understand the feasibility of this concept. From 1987 to 1989, Tank SY-101 was air lanced periodically. In 1989, the air lancing was performed almost daily. Each air-lancing operation introduced $28.3 \mathrm{~m}^{3}\left(1000 \mathrm{ft}^{3}\right)$ of air into the waste. The level data indicate that there is no systematically observed pattern, in terms of change of waste level and with respect to the air lancing. The level does not always increase or decrease after each air-lancing operation. Generally, the level continued to increase (in an average sense) until a small or large GRE occurred. In some cases, the level tended to stay constant or decreased slightly after several days following the air lancing. However, these small changes were insignificant because they did not change the level-time plot significantly.

The above observations suggest that introducing air in the waste does not immediately cause a rollover with an associated significant gas release. Adding air to the waste is expected to increase the level growth rate. This conclusion assumes that some fraction of added air will remain entrapped in the waste as bubbles. As a result, the waste may reach the neutral buoyancy point faster, resulting in a decrease in GRE periods between large GREs. After April 1987, the first four consecutive large GREs had GRE periods oflasted? 89, 77, 102, and 71 days, respectively. The average of these four values is $\sim 85$ days, which is less than the average historical GRE period of 105 days. The decrease in the GRE period supports the assumption of added gas volume caused by retained gases from air lancing.

These observations suggest that this concept would not offer an effective mitigation option for FG retention and release. Besides, the addition of oxygen may increase the gas generation. Also, additional oxidizer is being introduced into the waste, and thus, FG hazards in the waste are increased. Accumulation of air may also cause GREs larger than observed in DSTs if the concept is used as a long-term mitigation option. Data obtained from Tank SY-101 are not sufficient to make a definitive determination of the effect of lancing on gas generation and retention. The uniform mixing may not be provided.

The technology for air lancing is simple, available, and used. Maintenance, decontamination, and operation are relatively simple for this low-cost concept. 


\subsubsection{Steam Lancing of the Nonconvective Layer}

The operation and design of this concept are similar to air lancing, except that steam is used instead of air. In addition to the local mixing effects provided by air lancing, the use of steam adds other effects, such as herting and dilution. In addition, the condensation of steam can cause pressure pulses, resulting in additional mixing effects that are similar to those obtained using sonic waves (sonic agitation is discussed in Secs. 6.1.18 and 6.1.19).

Steam injection would alter the temperature of the tank. Increasing the temperature may be desirable for some tanks. The effect of heating and the dissolution of nitrate and nitrite salts is not linear with temperature. Solids of sodium carbonate start to crystallize at high temperatures because they are less soluble at higher temperatures. Heating also alters the gas composition. The condensed steam could cause more salts to dissolve, thus further reducing the solid fraction.

The adverse effects and design requirements are unknown. The waste chemistry can be affected. The risk of the concept is high in terms of adverse unexpected effects, and the concept is currently unproven. The operation of the ventilation system is limited to $80 \%$ humidity in the dome space. This limit may be exceeded.

The mechanical design, maintenance, and operation are similar to air lancing. It is a low-cost concept and rzquires relatively short times to be implemented.

\subsubsection{Nitrogen Lancing of the Nonconvective Layer}

This concept is another variant of air lancing. Mitigation effects are similar to those of air lancing, and thus the discussion of Sec. 6.1.6 applies. The lancing is proposed to be performed with nitrogen instead of air. Substituting nitrogen for air prevents the addition of oxygen into the waste.

\subsubsection{Sparging with Nitrogen}

The principle of this concept is to promote stirring by adding a gas as uniformly as possible throughout a plane at the bottom of the nonconvective layer. The principle is similar to that of nitrogen or air lancing, except that the gas is introduced more uniformly across the cross section of the tank. This promotes uniform mixing in the nonconvective layer. Mitigative features of the mixing concepts discussed earlier apply here also, except that mixing is expected to be less efficient than in pump mixing because of the lower energy available. This scheme has an additional mitigative feature in that the FG concentration in the bubbles is lower because of the added nitrogen. If the nitrogen is fed continuously, this would cause FG concentrations in the dome space to be lower also.

The rate and period of injection are key parameters of the operation and may result in adverse effects observed in air lancing; nitrogen bubbles may remain in the waste 
and cause faster waste level growth. The gas inventory may increase because of two effects: (1) the available surface area for diffusion of hydrogen from the liquid phase to the bubbles increases and (2) nitrogen bubbles may remain in the waste.

The suggested design has a central manifold with 10 gravity-activi ted distribution arms. The flow rate may be small enough to cause plugging of the holes of the distributor. The central manifold needs to be inserted into a riser at the middle of the tank. Some tanks already have equipment in the central riser. If another riser is used, the arms cannot be opened symmetrically and thus, some part of the waste may not be sparged. The opening of the arms also may be not possible for some tanks because of the equipment installed or harder wastes. The risk for successful operation is not high.

Contamination, maintenance, and operation of the design are relatively easy. The cost and schedule for this concept are similar to the mixer pump concept because engineering design and development and testing are not available.

\subsubsection{Using Inert Gas in the Dome Space}

The FG hazard exists only if the sufficient quantities of fuel and oxidizer exist simultaneously with an ignition source. This concept eliminates the FG hazard in the dome by removing the oxidizer. Although the waste generates its own oxidizer (nitrous oxide), in most of the tanks, the ratio of hydrogen to nitrous oxide is low to cause FG concentrations. Therefore, if the air in the dome space is eliminated/replaced by an inert gas such as nitrogen, the FG hazard would be mitigated.

A nitrogen generation plant with a backup liquid nitrogen supply would feed several tanks. The flow rate of the nitrogen would vary, depending on the rate of infiltration of air into the tank. The control system is expected to be simple and would consist mainly of a few valves to adjust the flow rate of the nitrogen and the ventilation flow to ensure a negative tank pressure.

This concept may work if the hydrogen and nitrous oxide are not at a flammable ratio. When a riser is opened, the system may not function as designed. However, the time to open a riser is not more than a few hours. The tank dome space would not be mixed with a significant amount of air during the short period of the riser being open.

The process of making liquid nitrogen consists of condensing atmospheric gases (principally nitrogen and oxygen), separating the liquefied gases, packaging and handling the liquids, and delivering the liquids. The most expensive part of this process is the packaging and handling, which is reflected in the relative costs for "cylinder" and "bulk" gas prices. In the US, liquid nitrogen usually costs $\sim \$ 2.00 /$ gal. when delivered in dewars and $\sim \$ 0.50 /$ gal. when delivered and pumped into a bulk storage tank. The density of liquid nitrogen is $0.81 \mathrm{gm} / \mathrm{cm}^{3}$. For a nitrogen purge of $200 \mathrm{scfm}, 560,000$ gal. of liquid nitrogen is required annually. At $\$ 0.50 /$ gal., the 
annual nitrogen cost would be $\$ 280,000$. That is relatively inexpensive compared to the $\$ 10,000,000$ cost of a mixer pump.

At a cost of less than $\$ 500,000$, the concept would be worth testing; this test would be a nitrogen purge for a few months, with liquid nitrogen as the sou ce of nitrogen. A key parameter in evaluating the effectiveness of a nitrogen purge is the infiltration of air. Experimental estimation of the infiltration of air would be easy to test by shutting the inlet air duct and measuring the pressure in the tank and the exhaust flow rate. Such data would enable us to calibrate a model of the ventilation system for design purposes.

Commercial nitrogen is produced by a variety of air separation processes, including cryogenic liquefaction and distillation, adsorption separation, and membrane separation. Air Products has a membrane system for making nitrogen. Depending on the required purity and flow rate, the PRISM Membrane Nitrogen System could save up to $50 \%$ on the cost of nitrogen as compared to traditional supply modes, such as liquid, inert gas generators, or compressed gas cylinders. Systems are available for flow rates up to $100,000 \mathrm{scfh}$ and for purity levels as high as $99.9995 \%$ with purification. Within each system, design flow rates and purities can be changed with the turn of a valve.

There are no installation hazards and or?need for decontamination. Safety assessment of this system would be generated quickly and inexpensively because the concept does not increase the frequency or consequences of GREs. The only new significant accident would be the increased frequency of pressurizing the dome.

The cost and schedule for this concept are very reasonable. All aspects of the engineering design and development are expected to be completed in $\sim 1 \mathrm{yr}$, at an estimated cost of $\$ 2,000,000$. The cascaded SSTs may need to be considered separately.

\subsubsection{Supernatant Liquid (Convective-Layer) Removal}

The episodic releases observed in Tank SY-101 are believed to be caused by a density instability in the tank; all or part of the nonconvective layer becomes neutrally buoyant relative to the convective layer, causing a rollover that could release large amounts of gas. The principle of this concept is to prevent density-instabilityinitiated rollovers by removing all or part of the convective layer. FG is expected to be released continuously after the removal of supernatant.

In addition, supernatant removal increases the dome volume; thus, even if episodic releases occur, the FG concentrations in the dome space are lower for the same release volume. If the dome volume increase is large enough, the FG concentration would be lower than $25 \%$ of the LFL, even if all of the retained gas is released. The height of convective layer in the tanks varies, and thus, this reduction in the FG concentration would not be achieved in some tanks. 
Another effect of supernatant liquid removal is that the heat load of the tank. This would affect the temperature of the waste, the solubility of the various components, and in turn the solubility of the solids fraction. The gas generation would be altered as a result of changes in the nonconvective-layer pressure, as well as a result of the poter:ial changes in the solids fraction. It is clear that the long-term behavior of FG in the waste could be altered by this scheme, and thus, additional analyses would be required to ascertain the extent of the changes. New data and analysis tools are available to assess the effect of this concept on the gas generation, retention, and release.

The equipment required for the concept is not complicated; a new?equipment design is not necessary because transfer pumps are available at the site. However, this scheme does involve the transfer of waste out of the tank, and therefore, receiver tanks are needed. Tank space projections would have to be considered. This is a passive mitigation concept. Maintenance or surveillance is not required after the implementation. The implementation risk would include a release of FG during removal of the convective layer. Using the evaporator is not recommended for this option. The overall risk for successful mitigation of FG hazards is medium.

\subsubsection{Heating below the Boiling Point}

This concept promotes the idea of preventing or reducing gas retention by dissolving salt solids. Heating affects the solubility of sodium salts and therefore the solids fraction of the nonconvective layer. Changes in the solids fraction affect gas retention parameters, such as waste strength and viscosity, and thus, trapped or attached gas bubbles in the nonconvective layer could be released. Heating also affects many other waste parameters, including the nonconvective-layer volume; the solid and liquid densities (and therefore the density ratio); the amount of dissolved gas, ionic strength, and liquid and solids composition; and the interparticle forces. Changes in temperature and waste composition affect the gas generation, heat load, and gas composition.

Quantification of the effect of heating on the various parameters is not straightforward. The effect of heating on the solubility differs from one salt to another. To complicate matters further, the effects typically are nonlinear with temperature.

Small-scale tests have been performed in the past. Initial data showed that the simulant did not entrap gas above $60^{\circ} \mathrm{C}$. However, the simulant used may not be representative of real waste. No real tests or analyses exist to show the feasibility of the concept in removing gas and preventing retention.

The operation of the ventilation system is limited to $80 \%$ humidity. Heating will evaporate more water, and therefore, the moisture limit may be exceeded. The heat load will vary and must be reevaluated. 
The difficulty with this concept is the method of heating. Heating may be achieved by lowering the ventilation flow rate or by heating the annulus with hot air to heat up or prevent heat losses. These two methods do not require a waste intrusion but may provide relatively low heating rates. Inserting a steam or electrical heater in the waste is another me.hod of faster heating. Intrusive heating methods, if provided from equipment installed into a riser, would result in nonhomegenity in the tank. A mixer pump may be required to provide uniform heating.

Engineering design and development and testing would require considerable effort. Operation and maintenance of equipment may not be as easy as other methods. Operating electrically active components in the waste may require safety evaluations. The method of decontamination of equipment is unknown at this point. However, the method is considered to be simple compared to equipment needed to implement more complex strategies (mixer pump) mechanically.

New data and analysis tools are available to address the issues raised above. The material balance calculations can be used to evaluate the solids fraction at different temperatures. This analysis also would provide estimates of expected gas inventory and gas compositions. These results to predict the effect of heating on the gas releases and retention can be done on a qualitative basis.

\subsubsection{Heating Briefly to the Atmospheric Boiling Point}

Rıference 2 notes that some laboratory tests performed on synthetic waste showed that brief heating of a complexed waste to atmospheric boiling point changes the way the organics interact with the solid phase. The solids form a nonconvective layer with a clear liquid after heat treatment. The nonconvective layer behaved as if no organic were present. Without heat treatment, the solids would not settle out of solution. The principle of the method is that the heat treatment could alter the surface-active nature of the organics and destroy their ability to trap gas bubbles in nonconvective layer.

The concept is not understood very well. Its applicability to real waste is questionable. The observed behavior in the laboratory does not necessarily imply that the concept would produce the expected mitigation effects in the tanks. Equipment and other aspects of this concept are similar to those for heating (see Sec. 6.1.13). Because there are serious questions regarding the principle of the concept, other factors are not considered.

\subsubsection{Organic Destruction by Heating}

Gas is generated in the waste by the decomposition of the organic complexants and by the radiolysis of water in the waste. This concept is proposed to eliminate the first of the above two generation mechanisms-gas generation by decomposition of the organic complexants can be eliminated if the organics are destroyed. The principle is to consume the organics by heating the waste to high temperatures and moderate pressures. The organics safety program provides the temperature where 
significant reaction occurs. The heating should yield a temperature range of 160 to $250^{\circ} \mathrm{C}$. Because the proposed scheme involves heating, the mitigative features of heating (discussed in Sec. 6.1.3) also need to be considered.

This concept has significant disadvantages. Fi“st, there is no proof of principle. In addition, the equipment design (reactor or a pressure vessel) is not known. The equipment may be placed outside or inside the tank. The reaction vessel may need containment. The concept must be tested with real waste, which may take 1 to $2 \mathrm{yr}$. The time of treatment may take too long, depending on the reactor design. Corrosion, upset conditions, gas generation, etc., need to be reevaluated. The overall risk is high. Also, this scheme addresses only one of the gas generation mechanisms, and thus, radiolytic generation still may be high enough that the FG hazard will not be eliminated.

\subsubsection{Organic Destruction by Chemical Means}

This concept is similar to the previous one, with the only difference being in the method used to destroy the organics. The principle is to destroy the organic in the waste by using the nitrate and nitrite present in the waste to oxidize the organic. Treatment with an oxidizing agent destroys the organic complexants and reduces the gas generation rate. Lower gas generation rates would result in lower gas fraction. Oxidants such as ozone or peroxide can be used. Other processes includes the use of ultraviolet light. Only the use of ozone is found to be feasible. Oxalate is postulated to be the fiical results of alkaline decomposition of organic using ozone. Other issues are similar to those discussed in Sec. 6.1.15.

\subsubsection{Dilution}

This concept promotes the idea of preventing or reducing gas retention by dissolving salt solids. In this sense, the mitigative features are similar to those of heating (see Sec. 6.1.13), except that the means of reducing the solids fraction is different. In dilution, the principle is to add caustic or other diluent to the nonconvective layer to dissolve some of the solids as well as to reduce the viscosity. Waste parameters affected by dilution are largely similar to those affected by heating (and discussed in Sec. 6.1.13).

The principle of the concept has been demonstrated in limited experiments. However these experiments did not prove that dilution reduces the retention. Data and analyses available to characterize dilution effects on gas releases are extremely limited. A small data base exists for the effect of dilution on waste properties such as solids fraction, viscosity, and yield strength. However, its applicability is limited to Tank SY-101. Limited analyses have been carried out for effects of dilution on gas releases in Tank SY-101.

Since 1992, additional characterization data have become available. Improved solubility models have been developed. The waste inventory before and after dilution can now be estimated using material balance calculations utilizing best- 
estimate solubility models for the major solid constituents in the waste. These include nitrates, nitrites, carbonates, and aluminates. The effect of the change in waste inventory on the waste strength and viscosity (gas retention) and gas generation are unknown. These effects can be estimated qualitatively using scaling rules and guidelines. Long term effects on wiste chemistry need to 'je determined.

FG-1 DSTs have limited dome space volumes to utilize this concept fully in eliminating the FG hazard. Addition of diluent reduces the dome space thus smaller GREs may result in FG concentrations above $25 \%$ of the LFL. The implementation of the concept may initiate large rollovers in some of the FG-1 DSTs. The addition of diluent from one riser would have local effects unless a mixing pump is used simultaneously. If some of the diluted waste is transferred to another tank, waste compatibility issues become important. This concept is a passive mitigation scheme but it increases the mass of waste for retrieval.

The equipment is simple; a turbine pump achieving a positive head pumps the caustic from a truck through a vertical pipe to nonconvective layer. The cost and schedule are estimated roughly as 2 million dollars and 6 months to 2 year for this concept.

\subsubsection{High Frequency Sonic Agitation}

High frequency sonic agitation is proposed to stimulate the release of stored FG by yielding the waste. The principle of this concept is to use pressure waves to yield the waste. The primary purpose is to release FG in a way that the FG concentration in the dome space is always less than $25 \%$ of the LFL. This concept does not change the composition of the gas significantly.

Injection of ultrasonic waves in nonconvective layer can be done in several ways:

- Compressional waveguides

- Piezoelectric transducer directly in waste

- Coupling through the wall

- Liquid whistles

Reference 2 concludes that tortional and flexural waveguides should not be used because they create particle motion in the fluid adjacent to the waveguide or have limited energy transmitted to the surrounding region.

The principle of the concept is to transmit acoustic energy of transducers located on one hand of the waveguide to the opposite end (reflector, retransmitter). The lower end retransmit the acoustic energy into the waste. The waveguide can be acoustically isolated. 
All electrical equipment is outside of the tank. The ultrasonic wave may agitate smaller bubbles. The high frequency acoustic wave can attenuate very fast that the zone of influence may be limited to a few meter or less. A multiple use of ultrasonic probes may be necessary to agitate the whole tank. Riser availability is limited in FG-1 DSTs.

There are some adverse effects of high frequency sonic agitation. These are

- Consolidation of particles (may result trapping gas beneath the consolidated mass thus enhancing retention),

- Sonochemistry (may create nitrite and $\mathrm{H}_{2} \mathrm{O}_{2}$ may alter the waste characteristics),

- Heating (heating may alter the solid fraction, more importantly the shock waves produce high-velocity interparticle collision that may cause the particles to melt. and local hot spots due the cavitation of liquid can occur, $5000^{\circ} \mathrm{C}$. This can initiate propagating exothermic reactions),

- Adverse effects on the tank wall,

- Generation of foam.

The concept has been tested in the laboratory and may take up to 18 months to build. Laboratory tests showed that bubbles migrate in a small scale tank. Migration of bubbles in large scale tank needs to be evaluated.

\subsubsection{Low Frequency Sonic Agitation}

This concept is similar to the previous one except that the frequency of the sonic wave is reduced. The use of low frequency sonic waves has two important effects; ait increases the diameter of bubbles that can be agitated, and b- it increases the attenuation distance. These advantages makes the low frequency agitation concept more attractive relative to ultrasonic agitation. It uses the same principles; pressure waves yield the waste causing bubbles to become buoyant and rise.

The deployment of low frequency sonic agitation devices would result in a more continuous release of gas and lower retention. Preliminary design of a sonic probe was already completed in 1994 . The probe is a cylindrical shell $18 \mathrm{ft}$. long and $11 \mathrm{in}$. in diameter, with an eccentric mass that rotates about a shaft. The selected design frequency is $\sim 100 \mathrm{~Hz}$.

A considerable number of experimental and analytical studies on various aspects of the sonic probe were carried out in 1993 and 1994. Different experimental studies relating to sonification used different media. Proof-of-principle experiments were carried out using vibrators in a tube filled with wet concrete. Experiments were 
conducted using waste simulants and actual tank waste from Tank SY-101 to investigate possible densification or strengthening as a result of sonification. Most experiments showed decreased strength over time, but at least one experiment showed that hardening is possible. The effects on waste in other tanks are also high',y uncertain.

The mechanism of waste yielding by sonification, and the criteria for yielding are needed for estimating gas release volumes. The attenuation characteristics as a function of the frequency are needed The attenuation of the waves in the waste is a function of several parameters including the bubble diameter. The range of bubble diameters in the waste remains highly uncertain. Therefore, the volume of sludge that can be yielded using this approach cannot be estimated with any degree of accuracy. Possible side-effects of sonification, such as densification, hardening, foaming, or adverse chemical reactions are unknown.

Maintenance, operability and decontamination of the sonic probe are relatively easy.

The cost is estimated about 2 million dollars. The estimated schedule for installation of the probe with all aspects resolved is $\sim 1$ year. There is a safety document for this concept.

\subsubsection{Spark Control}

As noted in Sec. 6.1.11, the FG hazard exists only if the sufficient quantities of fuel. and oxidizer exist simultaneously with an ignition source. This concept eliminates the FG hazard in the dome by removing the ignition source. Generally, the source of ignition could be classified as

1. electrical,

2. mechanical,

3. chemical,

4. thermodynamical,

systems or processes. The examples of ignition sources for these general systems or processes are given below.

Electrical Systems and Processes: Ignition of hydrogen mixtures requires only relatively low energy (a few $\mathrm{mJ}$ ) to be released into the mixture. Electrical equipment involving relays, circuits, lights, power switches, electric motors etc. can easily generate or involve such small amounts of energy under normal or failure conditions. Static electricity accumulation and discharge and arcs are important sources of electrical sparks.

NPFA or National Electric Code (NEC) codes are very useful to develop adequate design requirements for an intrinsically safe system. Meeting the requirements of 
these industrial codes to prevent the ignition of the flammable mixtures for each individual electrical equipment provides necessary protection. NEC and NFPA standards/codes recommend that a proper classification needs to be performed before the applicable guidelines are established.

Mechanical systems and process: The FG mixture can be ignited by mechanical sparks, ejection of hot gases solids, burning debris of sufficient size, number and temperature, frictional heating, failures leading frictional heating, mechanical sparks as a result of impacts of collisions of two solid bodies, fractures, plastic deformations of solid brittle materials.

Chemical Systems and Process: The exothermic reactions could ignite a flammable gas mixture if the reaction yields temperatures in excess of the autoignition temperature of the mixture. In this class, reactions between waste and solids, and reactions as a result of local heating or failures are considered. The termite flash reactions that could occur between the oxidized steel and aluminum is also concern.

Thermodynamic Systems and Processes: The temperature of a given system can yield ignition. For example compression of FG bubbles could yield temperatures in excess of autoignition temperature.

Prevention of frictional/mechanical sparks can be managed proper administrative controls. Designing ventilation systems meeting NFPA and NEC codes is a rclatively low cost option, about 2 million dollars per tank, compared to the cost of the mixer pump (10\$M). Today, the technology is available to minimize the spark sources in any equipment. However, it is not possible to eliminate the spark sources completely. This concept offers significant reduction in likelihood of spark, therefore the ignition of $F G$, with relatively low cost.

The implementation of concept would not take more than a year. The disadvantage of concept is that there are already some equipment in the FG-1 DSTs. The cost of upgrading these equipment for spark free environment may be high when removal and reinstallation of these equipment is considered.

At the start of this study, the Project hanford Management Contractor (PHMC) indicated that this option is being studied separately. Therefore, in the present report, consideration of this scheme is limited to this section only. However, it is important to note that this concept may be a sound and inexpensive mitigation option for some specific cases.

\subsubsection{Surfactant Addition to Modify Slurry Rheology}

This mitigation concept is based on the hypothesis that the surface activity of sludge causes it to gel or 'set up' at certain temperatures and concentrations and attain a strength that will trap the generated gas. The principle of this concept is that addition of surfactant to the waste may inhibit the ability to 'set' so that the gas could 
not be trapped but released continuously. Thus this mitigation scheme is intended to affect waste strength and viscosity by altering surface phenomena.

The principle of this concept has not been proven. A mixing methodology may be needed for effective dj-tribution of surfactan ${ }^{+} ;$in the nonconvective layer. Suitable surfactants for proposed effects are not identified for real wastes. The amount of surfactants is estimated as $1 \%$ of total volume. However, this estimate is not verified. The rate of surfactant addition and monitoring requirements are not known. This concept is at the conceptual theoretical stage. The surfactant added may be consumed by time through the chemical decomposition. So that a continuos addition of surfactant may be required.

Depending upon the implementation requirements and research needs to prove the concept the cost and schedule would be significant. This concept was consider to have a high risk.

\subsubsection{Surfactant Addition to Reduce Bubble Attachment}

Laboratory tests have shown that organic compounds and their decomposition products alter the surface properties of the waste solids making them slightly hydrophobic (Ref. 2). Experiments showed that the contact angle between liquid and simulated waste is zero, that is, liquid spreads over the solids. When organic was present in the waste simulant, liquid drops were observed to have a non-zero contact angle. This property causes the bubble to attach to a solid particle or a nucleated gas bubble to stick to solid surface. The principle of this mitigation concept is that bubble attachment could be reduced, and a more steady gas release can be obtained, if the weeting characteristics are altered. The addition of surfactant is intended to counteract the effect of the organic present, and reduce the contact angle so that bubbles cannot attach to the solid particles. As a result, bubbles migrate out of the slurry preventing the accumulation of gas. The generated gas would then be released in a continuous fashion.

Concerns expressed in the previous section are applicable to this concept. Basically, the overall uncertainty and risk of the concept are high.

\subsubsection{Removal of Organic Complexants by Supercritical Extraction}

This concept is similar to those of Secs. 6.1 .15 and 6.1.16, with the only difference being in the method used to destroy the organics. Supercritical extraction removes the organic complexants and reduces the gas generation rate. Lower gas generation rates would result in lower gas fractions.

The technology for the proposed concept is not sufficiently advanced. The concept is considered in theory. Water and carbon dioxide are the primary fluids used in the industrial application of supercritical extraction. Water cannot be used as the working fluid with an aqueous system. Carbon dioxide would dissolve in the alkaline waste creating addition sodium carbonate. This concept is not based on a 
good sound principle and there is no proof of principle. Other judgment factors are not discussed further.

\subsubsection{Removal of Radioactive Isotopes}

As noted in Sec. 6.1.15, gas is generated in the waste in two main ways: by the decomposition of the organic complexants, and by the radiolysis of water in the waste. This concept is proposed to eliminate the latter generation mechanismsgas generation by radiolysis can be eliminated if the radioactive isotoopes are removed. Lower gas generation rates would result in lower gas fractions. This concept does not eliminate the gas generation but reduces it. It does not effect the retention mechanism directly, but may do so indirectly.

The approach has several drawbacks. Even if radiolytic generation is eliminated, chemical decomposition of the organics will still produce FG. Reducing the temperature of waste may cause solid fraction to increase and the chemical gas generation rate to decrease. Increasing the solid fraction would also enhance retention for tanks rich in nitrite and nitrate. For tanks rich in carbonate this effect would be reversed. Also, the radioactive isotopes remvoed from these tanks will still have to be stored elsewhere.

The primary radioactive isotopes are cesium and strontium. Process to recover cesium and strontium from the waste were operated in B Plant. The technology is available for this concept. However, the concept require equipment to dilute and retrieve the waste. It may require additional tanks for storage. The process equipment is complicated and costly. The schedule to achieve the mitigation may take 5 years. Operation, maintenance, and decontamination requirements are also complicated. The retrieval of the waste require well characterization of the tank content before engineering are developed. The waste characterization requirements is the main roadblock of the concept. A pilot plant may be necessary to demonstrate that the process works as designed. This is a high cost concept.

\subsubsection{Separation of High Molecular Weight Components by Ultrafiltration}

This concept is identified in Ref. 2. However, the nature of the high molecular weight compounds are not clear. This concept is not evaluated further because need for literature survey.

\subsubsection{Solvent Extraction of Select Chemical Species}

Removing the select chemical species could lower gas generation rate. Lower gas generation rates would result in lower gas fractions. This concept is similar to concept IV.1.23. However, this concept emphasis the extraction of species other than the ${ }^{137} \mathrm{Cs}$. The technology status of the concept is not well understood. 


\subsubsection{Removal of Aluminate}

Recent review of data on FG-1 DSTs indicated that tanks rich in aluminate tend to retain more gases. The physical mechanism for this process is not clear, but naturally, the empirical observations suggest that removal of the aluminate would be a feasible approach to decrease retention, and thus mitigate the FG hazard. Aluminate removal reduces the mass of solids in the waste. Aluminate acts as a catalyst in some of the gas generating reactions. Removing aluminate reduces the gas generation.

The technology proposed for this concept is similar to the Bayer process for commercial production of aluminate from bauxite. The idea is at conceptual stage, so engineering design and development, as well as safety documentation would have to be prepared.

The concept does not eliminate gas retention completely. The amount of aluminate may be significant in some tanks. Removal of this material would require new tanks for storage or identification of processes for disposal. The time requirement (rate of removal) is unknown. A pilot plant may be needed. The overall risk is high.

\subsubsection{Removal of Sodium Carbonate}

Data reconciliation studies of FG-1 DSTs reveal that tanks rich in sodium carbonates tends to exhibit episodic releases. The principle of this mitigation concept is to reduce or eliminate episodic release by removing the sodium carbonate. Removing sodium carbonate reduces the mass of solids in the waste. It could prevent/reduce buoyant displacement and therefore likelihood of rollovers. Sodium carbonate is a major solids in most of salt cakes.

The technology is not known. Removal of material requires more storage tanks or disposal techniques. Proof of principle does not exist. Research and development is need for this concept. The overall risk is high.

\subsubsection{Addition of Mineral Forming Agents}

The principle of this concept is that gas generation can be reduced by reducing the aluminum concentration. This concept promotes addition of mineral-forming chemicals (e.i. $\mathrm{SiO} 2)$ to reduce the dissolved aluminum concentration. It was proposed based on an observation that a simulated solution containing no aluminum yields no gas. The chemical mechanism is not understood very well. Some studies in fact have observed no effect of aluminum concentration on the rate of gas generation. So proof of principle needs to be demonstrated.

There is significant amount of aluminum in the FG-1 tanks. Large amounts of mineral-forming agent may be needed to obtain acceptably low retention. The FG-1 tanks have limited volumes for material addition. Thus, the process may require 
addition and removal of materials from tanks. The equipment required for such an operation is significant. Maintenance and operation of process equipment is expected to be complicated. This is a high risk concept.

\section{1.?. Lowering $\mathrm{pH}$ of the Waste}

The principle of this concept is that gas generation can be reduced by lowering the $\mathrm{pH}$ of the waste. Laboratory tests showed that the gas generation is a first order function of $\mathrm{pH}$. The $\mathrm{pH}$ can be lowered using acid or an acidic gas.

There are several disadvantages of this concept. First, the addition of concentrated acid to strong base may be a safety hazard. The operating safety requirements (OSRs) specify a minimum $\mathrm{pH}$ level of 8 . The concept may be limited to tanks those have enough head space.

Proof of principle needs to be demonstrated using real waste. A minimum of $1 \mathrm{yr}$ would be required to establish proof of principle. The chances of success are believed to be low.

\subsubsection{Hydroxide Addition}

This mitigation concept is based on the hypothesis that gas is retained in the waste because an amorphous alumina gel is formed as a result of acidification of the waste due to carbon dioxide production or absorption. The principle of this concept is that hydroxide addition prevents the formation of alumina gels. Thus this mitigation scheme is intended to affect waste strength and viscosity by altering a postulated gas retention mechanism.

This concept was not considered in Ref. 2. Proof of principle needs to be demonstrated. There is conflicting evidence on the proposed retention mechanism. Bubbling carbon dioxide through a waste simulant produced an alumina gel. However, there are tanks with high hydroxide concentrations with significant retained gas inventories.

More investigation is needed to establish the feasibility of this approach. The process technology needs to be designed. Addition of material to tanks is not desired. The overall risk is high.

\subsubsection{Cooling the Waste}

Cooling of the waste reduces the rate of gas generation by chemical decomposition. Lower gas generation rate results in lower gas inventories. Cooling may result in higher convective layer densities. The likelihood of rollovers with higher convective layer densities reduces. However, the cooling may increase the solid fraction for tanks rich in nitrates/nitrites. The retention may be enhanced as a result of increase in solid fraction. The trend is reversed when there is significant 
carbonates in the tank. The hydrogen concentration would be enhanced with cooling.

Equipment for implementing the concept would be a heat exchanger placed in the $\mathrm{C}^{-1}$ ayer. The circulation of low temperature gas in the head space or annulus of the tanks is also possible.

Technology for the concept is available and may be relatively inexpensive. Operation and maintenance are not expected to be complicated. However, safety study is needed to evaluate the risk of malfunctioning equipment in the tank.

The major drawback of the concept is the risk of increasing the retention. As noted in Sec. 6.1.13, new data and analysis tools are available to address the issues raised above. The material balance calculations can be used to evaluate the solid fraction at different temperatures. This analysis also would provide estimates of expected gas inventory and gas compositions.

\subsubsection{Addition of Free Radical Scavenger}

The principle of this mitigation concept is that radiolytic gas generation can be reduced by increasing the concentration of free radical scavengers in the waste. These include nitrates, nitrites, and carbonates. This concept was not considered in Ref. 2. Literature reports indicate that $\mathrm{G}\left(\mathrm{H}_{2}\right)$ decreases with the addition of free zadical scavengers.

This scheme addresses only the radiolytic component of generation. Chemical generation is unaffected, and in fact, may be increased by the addition of these compounds. The proof of principle has not been demonstrated. Considerably more studies will be required before the feasibility of this approach can be determined.

\subsubsection{Retrieval}

Retrieval is the ultimate objective of waste disposal. The principle is to eliminate the FG hazard by fulfilling the ultimate disposal objective. However, the retrieval process is not simple includes significant equipment. Waste may need to be diluted and mixed before it is transferred. The concept also requires determination of a disposal method. From the point of view of mitigating FG hazards, the cost and schedular limitations are very high.

\subsubsection{Solidification of Waste}

The gas is retained in the waste when the buoyancy force on bubbles is less than the strength of material (shear strength). The principle of this concept is to immobilize the bubbles completely by increasing the shear strength. The waste can be solidified to a degree that the FG gas cannot escape from the solidified waste if generated. The gas generation is also reduced if the waste is solidified. 
Solidification can be achieved in several ways; freezing, adding chemicals or bentonite. The idea is new and is at a very conceptual stage. The freezing may be considered as a way to solidify. Other irreversible solidification concepts are not preferable. Freezing may require significant nitrogen. Because this is at such an early conceptual stage, considerable research s, id development will be required.

\subsubsection{Multiport risers (MPRs)}

All the mitigation concepts discussed so far concentrated on the prevention or reduction of the FG hazard by trying to eliminate one or more of the conditions necessary to prevent an ignition in the tank. This concept proposes means to mitigate the consequenre of a FG ignition. Ignition is assumed to occur, and the consequences are then sought to be minimized to within acceptable limits.

Explosion prevention decreases the probability of occurrence by controlling or removing ignition sources and modifying the process to eliminate an explosible atmosphere. Protection methods manage the hazard by reacting to the explosion. Protection techniques include containment, isolation, suppression, and venting. Containment allows the explosion to fully develop and relies on the strength of the process equipment to retain the post explosion atmosphere. Isolation reacts to the explosion by stopping the spread of the explosion from the point of origin. Suppression and venting react to the explosion and minimize the hazard by decreasing the explosion pressure to a safe level.

The proposed concept of implementing multiport risers to the tank is a venting method to control the explosion. The multiport riser is a device to provide pressure relief during a postulated burn accident in the dome space. It has several pressure relief panels that provides a containment to the tank vapor and gas environment up to a design pressure. Below the design pressure the panels can not be opened. Above the design pressure panels are open to release the pressure inside the tank.

The MPRs for already designed and implemented to Tank SY-101. They are very inexpensive to fabricate, install and operate. The expected function is demonstrated to work.

In this concept the burning of FG is allowed to run its course without developing damaging pressures within the tank. The estimation of tank volume, geometry, resulting peak burn pressure and rate of increase of pressure will determine the necessary vent area to prevent pressures excess of dynamic and static structural limits.

Ignition characteristics (flammability) of FG mixtures of concern and associated flame speeds have recently been determined experimentally. The use of the new data and available tools to estimate the burn peak pressure and rate of increase of pressure can successfully determine the necessary design requirements. This option is a low cost concept and relatively easy to implement. Expe 


\subsubsection{Dome Explosion Suppression}

As explained above, another possible way to mitigate the consequence of an explosion is to use of suppression systems. Suppression discharges a material into the equipment to stop the explosion from reveloping fully. Berause suppressant agent creates an atmosphere that will no longer allow flame propagation, damaging pressures from the ignition of FG will not develop.

Suppression system first detects the ignition through measurement of pressure and extinguishes the flame with a suppressant agent. Effective and timely extinguishing of the explosion depends on the rapid delivery of right amount of suppressors. The proper location of burn and early detection determines the implementation of an optimum suppression system. Use of multiple suppression systems increases the performance.

The suppression system costs more relative to venting systems. A small pilot system may be needed to demonstrate that concept works for worse postulated conditions. The development and design cost should not be high relative to the cost of mixer pump concept.

\subsubsection{Ventilation}

Ventilating tank dome space prevents FG accumulation. This concept is already used in FG-1 tanks. Typical flow rates of ventilation system is up to $500 \mathrm{scfm}$. The ventilation reduces the time of risk of FG concentration in the dome space for GREs with low release rates. The flow rate must be increased significantly if a GRE with a rate higher than $1000 \mathrm{scfm}$ occur. High flow rates causes the tank pressure to decrease below limits allowable by OSRs. Therefore, this concept is identified but not considered in the rest of the evaluation.

\subsection{Summary of Mitigation Strategies Identifications}

The following table summarizes the mitigation strategies, their physical principles, classification and gives information about its status. 


\section{TABLE 6-1}

MITIGATION STRATEGIES FOR FG-1 DSTS

\begin{tabular}{|c|c|c|c|}
\hline $\begin{array}{c}\text { Mitigation } \\
\text { Strategy }\end{array}$ & $\begin{array}{c}\text { Mitigation } \\
\text { Mechanism \& } \\
\text { Cause }\end{array}$ & Physical Principles & History/Comments \\
\hline $\begin{array}{l}\text { Pump Mixing (Horizontal } \\
\text { Jet Mixing) }\end{array}$ & $\begin{array}{l}\text { Gas retention and } \\
\text { release. } \\
\text { Prevent nonconvective } \\
\text { layer formation. } \\
\text { Reduction of } \\
\text { nonconvective layer } \\
\text { volume. } \\
\text { Reduction in yield } \\
\text { strength and viscosity. }\end{array}$ & $\begin{array}{l}\text { Eliminate nonconvective } \\
\text { layer by mixing. } \\
\text { Prevent settling and } \\
\text { formation of nonconvective } \\
\text { layer. } \\
\text { Control gas release rate and } \\
\text { amount and frequency. }\end{array}$ & $\begin{array}{l}\text { Successfully applied in SY-101. } \\
\text { Reduced retained gas inventory } \\
\text { and eliminated episodic GREs. } \\
\text { Maintained a constant waste } \\
\text { level: } \\
\text { High cost concept. }\end{array}$ \\
\hline Vertical Jet Mixing & $\begin{array}{l}\text { Gas retention and } \\
\text { release. } \\
\text { Prevent nonconvective } \\
\text { layer formation. } \\
\text { Reduction of } \\
\text { nonconvective layer } \\
\text { volume. } \\
\text { Reduction in yield } \\
\text { strength and viscosity. }\end{array}$ & $\begin{array}{l}\text { Eliminate nonconvective } \\
\text { layer by mixing. } \\
\text { Prevent settling and } \\
\text { formation of nonconvective } \\
\text { layer. } \\
\text { Control gas release rate and } \\
\text { amount and frequency. }\end{array}$ & $\begin{array}{l}\text { Considered in theory by } \\
\text { Hanford. } \\
\text { High cost concept. }\end{array}$ \\
\hline $\begin{array}{l}\text { Nonconvective Layer } \\
\text { Recirculation } \\
\text { (air lift circulators, liquid } \\
\text { pistons and others) }\end{array}$ & $\begin{array}{l}\text { Gas retention and } \\
\text { release. } \\
\text { Prevent nonconvective } \\
\text { layer formation. } \\
\text { Reduction of } \\
\text { nonconvective layer } \\
\text { volume. } \\
\text { Reduction in yield } \\
\text { strength and viscosity. }\end{array}$ & $\begin{array}{l}\text { Eliminate nonconvective } \\
\text { layer by low velocity } \\
\text { mixing. } \\
\text { Prevent settling and } \\
\text { formation of nonconvective } \\
\text { layer. } \\
\text { Control gas release rate and } \\
\text { amount and frequency. }\end{array}$ & $\begin{array}{l}\text { Considered in theory by } \\
\text { Hanford. } \\
\text { Scaled tests shows that liquid } \\
\text { piston will work. } \\
\text { Low cost concept. }\end{array}$ \\
\hline Past Practice Sluicing & $\begin{array}{l}\text { Gas release. } \\
\text { Reduction of } \\
\text { nonconvective layer } \\
\text { volume. } \\
\text { Reduction in yield } \\
\text { strength and viscosity }\end{array}$ & $\begin{array}{l}\text { Eliminate nonconvective } \\
\text { layer by mixing. } \\
\text { Control gas release rate and } \\
\text { amount and frequency. }\end{array}$ & $\begin{array}{l}\text { New mitigation concept. } \\
\text { The equipment and operation of } \\
\text { the equipment is similar to } \\
\text { sluicing, which has been done at } \\
\text { Hanford. } \\
\text { Medium cost concept. } \\
\text { May need to operate } \\
\text { periodically. }\end{array}$ \\
\hline Mechanical Stirring & $\begin{array}{l}\text { Gas retention and } \\
\text { release. } \\
\text { Prevent nonconvective } \\
\text { layer formation. } \\
\text { Reduction of } \\
\text { nonconvective layer } \\
\text { volume. } \\
\text { Reduction in yield } \\
\text { strength and viscosity. }\end{array}$ & $\begin{array}{l}\text { Eliminate nonconvective } \\
\text { layer by low velocity } \\
\text { mixing. } \\
\text { Prevent settling and } \\
\text { formation of nonconvective } \\
\text { layer. } \\
\text { Control gas release rate and } \\
\text { amount and frequency. }\end{array}$ & $\begin{array}{l}\text { Considered in theory by } \\
\text { Hanford. } \\
\text { No engineering design. } \\
\text { No proof of principle. } \\
\text { No Laboratory data. } \\
\text { High cost. }\end{array}$ \\
\hline $\begin{array}{l}\text { Water Lancing } \\
\text { nonconvective Layer }\end{array}$ & $\begin{array}{l}\text { Gas release and } \\
\text { retention. } \\
\text { Reduction in gas } \\
\text { retention. } \\
\text { Dissolves solids and } \\
\text { release gas/. } \\
\text { Nonconvective layer } \\
\text { volume is reduced. }\end{array}$ & $\begin{array}{l}\text { Limited mixing of the } \\
\text { nonconvective layer } \\
\text { increases the rate of gas } \\
\text { release preventing the } \\
\text { waste from reaching a } \\
\text { neutral buoyancy } \\
\text { condition. }\end{array}$ & $\begin{array}{l}\text { New mitigation concept. } \\
\text { Used in SY-101 from 1984-1986. } \\
\text { Eliminated GREs for a period of } \\
\text { 15 months, but level data } \\
\text { indicates that gas inventory was } \\
\text { not reduced. Although two } \\
\text { small GREs occurred during } \\
\text { water lancing, better procedures } \\
\text { may eliminate all GREs. } \\
\text { Low cost. } \\
\text { Limited by available dome space } \\
\text { volume. }\end{array}$ \\
\hline
\end{tabular}


TABLE 6-1 (cont)

MITIGATION STRATEGIES FOR FG-1 DSTS

\begin{tabular}{|c|c|c|c|}
\hline $\begin{array}{c}\text { Mitigation } \\
\text { S'ategy }\end{array}$ & $\begin{array}{c}\text { Mitigation } \\
\text { Mechanism \& } \\
\text { Cause }\end{array}$ & Physical Principles & History/Comments \\
\hline $\begin{array}{l}\text { Air Lancing } \\
\text { nonconvective } \\
\text { Layer }\end{array}$ & $\begin{array}{l}\text { Gas release } \\
\text { Reduction in gas retention } \\
\text { Mixing and agitation }\end{array}$ & $\begin{array}{l}\text { Limited mixing of the } \\
\text { nonconvective layer increases } \\
\text { the rate of gas release preventing } \\
\text { the waste from reaching a neutral } \\
\text { buoyancy condition. }\end{array}$ & $\begin{array}{l}\text { New mitigation concept. } \\
\text { Used in SY-101 from 1986- } \\
\text { 1989. It did not eliminate } \\
\text { GREs and it increased gas } \\
\text { inventory. } \\
\text { May not provide uniform } \\
\text { mixing. } \\
\text { Low cost concept. }\end{array}$ \\
\hline $\begin{array}{l}\text { Steam Lancing } \\
\text { nonconvective } \\
\text { Layer }\end{array}$ & $\begin{array}{l}\text { Gas release and retention. } \\
\text { Mixing and agitation. } \\
\text { Dissolution of solids. } \\
\text { Reduction in nonconvective } \\
\text { layer volume. } \\
\text { Yielding the waste by } \\
\text { pressure pulses caused by } \\
\text { condensation. }\end{array}$ & $\begin{array}{l}\text { Steam addition has mixing, } \\
\text { dilution, heating. } \\
\text { Dissolves solids. } \\
\text { Reduces solid fraction. } \\
\text { Mixing by steam bubbles. } \\
\text { Condensation can yield the } \\
\text { waste and cause bubbles more } \\
\text { buoyant. }\end{array}$ & $\begin{array}{l}\text { New mitigation concept. } \\
\text { No proof of principle. } \\
\text { No laboratory or real data. } \\
\text { High risk. } \\
\text { Low cost. } \\
\text { Possible adverse effects. }\end{array}$ \\
\hline $\begin{array}{l}\text { Lancing with } \\
\text { Nitrogen }\end{array}$ & $\begin{array}{l}\text { Gas release. } \\
\text { Reduction in gas retention } \\
\text { Mixing and agitation }\end{array}$ & $\begin{array}{l}\text { Limited mixing of the } \\
\text { nonconvective layer increases } \\
\text { the rate of gas release preventing } \\
\text { the waste from reaching a neutral } \\
\text { buoyancy condition. }\end{array}$ & $\begin{array}{l}\text { New mitigation concept. } \\
\text { May not provide uniform } \\
\text { mixing. } \\
\text { Low cost concept. }\end{array}$ \\
\hline Nitrogen Sparging & $\begin{array}{l}\text { Gas release and retention. } \\
\text { Decreases FG concentration } \\
\text { in bubbles. } \\
\text { Reduction in gas retention } \\
\text { Dome space control. }\end{array}$ & $\begin{array}{l}\text { Limited mixing of the } \\
\text { nonconvective layer increases } \\
\text { the rate of gas release preventing } \\
\text { the waste from reaching a neutral } \\
\text { buoyancy condition. } \\
\text { Also, nitrogen reduces flammable } \\
\text { gas concentrations in the } \\
\text { bubbles. }\end{array}$ & $\begin{array}{l}\text { Similar to air lancing which } \\
\text { did not work as a means of } \\
\text { reducing GREs. } \\
\text { Low flow rates may plug the } \\
\text { holes. } \\
\text { Cause faster level growth. } \\
\text { May increase the magnitude } \\
\text { of GRE. } \\
\text { May increase gas inventory. }\end{array}$ \\
\hline $\begin{array}{l}\text { Inerting Dome } \\
\text { Space }\end{array}$ & Dome space oxidizer control & $\begin{array}{l}\text { Eliminate flammable gas hazard } \\
\text { in the dome by removing the } \\
\text { oxidizer. } \\
\text { No installation hazard }\end{array}$ & $\begin{array}{l}\text { New mitigation concept. } \\
\text { Need to know gas } \\
\text { composition. } \\
\text { Does not work when riser I } \\
\text { open long time. } \\
\text { Nitrogen plants are available } \\
\text { with reasonable costs.. }\end{array}$ \\
\hline $\begin{array}{l}\text { Supernatant } \\
\text { Liquid Removal }\end{array}$ & $\begin{array}{l}\text { Gas generation, retention } \\
\text { and release, and dome space } \\
\text { control. } \\
\text { Reduction in gas retention. } \\
\text { Reduction is bubble } \\
\text { pressure. }\end{array}$ & $\begin{array}{l}\text { Episodic GREs are eliminated. } \\
\text { Decreases flammable gas } \\
\text { concentration in the dome by } \\
\text { increasing dome volume. Reduces } \\
\text { moles of retained gas by reducing } \\
\text { pressure of nonconvective layer. } \\
\text { Waste level increase due to } \\
\text { expansion. }\end{array}$ & $\begin{array}{l}\text { Used in Project } W-320 \text { to } \\
\text { eliminate the possibility of a } \\
\text { flammable gas hazard in AY- } \\
102 \text { after sluicing of C-106 } \\
\text { waste. } \\
\text { Equipment is not complex. } \\
\text { A storage tank may be } \\
\text { required. } \\
\text { Medium cost concept. }\end{array}$ \\
\hline Heating & $\begin{array}{l}\text { Gas retention, generation } \\
\text { and release. } \\
\text { Reduction of nonconvective } \\
\text { layer volume by decreasing } \\
\text { solid fraction. }\end{array}$ & $\begin{array}{l}\text { Heating could dissolve the solids } \\
\text { in the nonconvective layer and } \\
\text { reduces the volume. } \\
\text { Increases gas generation. } \\
\text { Could release gas. } \\
\text { Some salts may not be dissolved. } \\
\text { Changes gas composition. }\end{array}$ & $\begin{array}{l}\text { Considered as a possibility } \\
\text { for } S Y-101 \text { but detailed } \\
\text { analysis was not performed. } \\
\text { Increased gas generation rate } \\
\text { could result in increased } \\
\text { nonconvective layer gas } \\
\text { fraction. } \\
\text { Cost could be relatively high. } \\
\text { Intrusive heating may require } \\
\text { mixing. }\end{array}$ \\
\hline
\end{tabular}


TABLE 6-1 (cont)

MITIGATION STRATEGIES FOR FG-1 DSTS

\begin{tabular}{|c|c|c|c|}
\hline $\begin{array}{c}\text { Mitigation } \\
\text { Strategy }\end{array}$ & Classification & Physical Principles & History/Comments \\
\hline $\begin{array}{l}\text { Heat Briefly to } \\
\text { Atmospheric } \\
\text { Boiling Point }\end{array}$ & $\begin{array}{l}\text { Gas retention } \\
\text { Reduction in gas retention } \\
\text { by altering the surface } \\
\text { characteristics. }\end{array}$ & $\begin{array}{l}\text { Brief heating of waste to boiling } \\
\text { point changes the rheology and } \\
\text { reduces gas retention. The } \\
\text { ability to trap gas is reduced. }\end{array}$ & $\begin{array}{l}\text { Test with an SY-101 waste } \\
\text { simulant in } 1980 \text { indicates } \\
\text { that heating and cooling } \\
\text { causes a change in the waste } \\
\text { rheology. } \\
\text { Proof of principle for real } \\
\text { waste is unknown. }\end{array}$ \\
\hline $\begin{array}{l}\text { Organic } \\
\text { Desªction by } \\
\text { Heating }\end{array}$ & $\begin{array}{l}\text { Gas generation. } \\
\text { Reduction in gas retention } \\
\text { by reducing the amount of } \\
\text { organics. }\end{array}$ & $\begin{array}{l}\text { Gas generation is primarily the } \\
\text { result of decomposition of the } \\
\text { organic complexants in the } \\
\text { waste. Heating destroys the } \\
\text { organic complexants and reduces } \\
\text { the gas generation rate. Lower } \\
\text { gas generation rates would result } \\
\text { in lower gas fractions. }\end{array}$ & $\begin{array}{l}\text { Considered in theory by } \\
\text { Hanford but not pursued. } \\
\text { Heating should yield } \\
\text { temperatures } 160-250^{\circ} \mathrm{C} \text { for } \\
\text { organic reactions. }\end{array}$ \\
\hline $\begin{array}{l}\text { Organic } \\
\text { Destruction by } \\
\text { Chemical Means }\end{array}$ & $\begin{array}{l}\text { Gas generation. } \\
\text { Reduction in gas retention } \\
\text { by reducing the amount of } \\
\text { organics. }\end{array}$ & $\begin{array}{l}\text { Gas generation is primarily the } \\
\text { result of decomposition of the } \\
\text { organic complexants in the } \\
\text { waste. Treatment with an } \\
\text { oxidizing agent destroys the } \\
\text { organic complexants and reduces } \\
\text { the gas generation rate. Lower } \\
\text { gas generation rates would result } \\
\text { in lower gas fractions. }\end{array}$ & $\begin{array}{l}\text { Considered in theory by } \\
\text { Hanford but not pursued. }\end{array}$ \\
\hline Silution & $\begin{array}{l}\text { Gas retention and release. } \\
\text { Reduction of nonconvective } \\
\text { layer volume and solid } \\
\text { fraction. }\end{array}$ & $\begin{array}{l}\text { Water or dilute caustic solution } \\
\text { is added to the waste. Some of } \\
\text { the soluble salts are dissolved } \\
\text { reducing the volume of the } \\
\text { nonconvective layer. }\end{array}$ & $\begin{array}{l}\text { Studied extensively as a } \\
\text { passive mitigation strategy } \\
\text { for SY-101. } \\
\text { Limited data. } \\
\text { Improved models and data are } \\
\text { available for re-assessment. }\end{array}$ \\
\hline $\begin{array}{l}\text { High Frequency } \\
\text { Sonic Probe }\end{array}$ & $\begin{array}{l}\text { Gas release and retention. } \\
\text { Reduction in retention by } \\
\text { yielding the waste and } \\
\text { allowing bubbles to become } \\
\text { buoyant. }\end{array}$ & $\begin{array}{l}\text { Microscale mixing induced by } \\
\text { ultrasound increases the rate of } \\
\text { bubble release from the } \\
\text { nonconvective layer. } \\
\text { Prevents episodic gas releases } \\
\text { and provides a continuos gas } \\
\text { release. }\end{array}$ & $\begin{array}{l}\text { Demonstrated on a small } \\
\text { scale with Agnew's simulated } \\
\text { waste tank. Calculations of } \\
\text { the attenuation rate indicates } \\
\text { that several probes would be } \\
\text { needed on a tank to be } \\
\text { effective. } \\
\text { Attenuation distance is small. } \\
\text { Multiple probes may be } \\
\text { necessary to provide a } \\
\text { uniform release. } \\
\text { Bubble migration in a large } \\
\text { scale tank needs to be } \\
\text { addressed. }\end{array}$ \\
\hline $\begin{array}{l}\text { Low Frequency } \\
\text { Sonic Probe }\end{array}$ & $\begin{array}{l}\text { Gas release and retention. } \\
\text { Reduction in retention by } \\
\text { yielding the waste and } \\
\text { allowing bubbles to become } \\
\text { buoyant. }\end{array}$ & $\begin{array}{l}\text { Microscale mixing induced by } \\
\text { ultrasound increases the rate of } \\
\text { bubble release from the } \\
\text { nonconvective layer. } \\
\text { Prevents episodic gas releases } \\
\text { and provides a continuos gas } \\
\text { release. }\end{array}$ & $\begin{array}{l}\text { Considered in theory by } \\
\text { Hanford. } \\
\text { Bubble migration in a large } \\
\text { scale tank needs to be } \\
\text { addressed. Solidification } \\
\text { issue needs to be resolved. } \\
\text { Design and SA exists. } \\
\text { May be a low cost concept. } \\
\end{array}$ \\
\hline
\end{tabular}

TABLE 6-1 (cont)

MITIGATION STRATEGIES FOR FG-1 DSTS 


\begin{tabular}{|c|c|c|c|}
\hline $\begin{array}{c}\text { Mitigation } \\
\text { Strategy }\end{array}$ & Classification & Physical Principles & History/Comments \\
\hline Spark Control & Dome space control. & $\begin{array}{l}\text { Prevent ignition of flammable } \\
\text { gases by eliminating the ignition } \\
\text { sources. The likelihood of } \\
\text { ignition } w^{\prime} \text {. ld be reduced } \\
\text { significantly. }\end{array}$ & $\begin{array}{l}\text { New mitigation concept. } \\
\text { Required in LANL's safety } \\
\text { assessments of Rotary Mode } \\
\text { Core Sampling and Salt Well } \\
\text { Pumping. }\end{array}$ \\
\hline $\begin{array}{l}\text { Surfactant } \\
\text { Addition to } \\
\text { Modify Slurry } \\
\text { Rheology }\end{array}$ & Reduction in gas retention. & $\begin{array}{l}\text { Addition of the surfactant would } \\
\text { reduce interparticle forces which } \\
\text { would result in a reduction in } \\
\text { slurry strength and apparent } \\
\text { viscosity }\end{array}$ & $\begin{array}{l}\text { Considered in theory by } \\
\text { Hanford. }\end{array}$ \\
\hline $\begin{array}{l}\text { Surfactant } \\
\text { Addition to } \\
\text { Reduce Bubble } \\
\text { Attachment }\end{array}$ & Reduction in gas retention. & $\begin{array}{l}\text { Addition of surfactant would } \\
\text { prevent bubbles from attaching to } \\
\text { particles. The unattached } \\
\text { bubbles would migrate out of the } \\
\text { slurry preventing the } \\
\text { accumulation of gas. }\end{array}$ & $\begin{array}{l}\text { Considered in theory by } \\
\text { Hanford. }\end{array}$ \\
\hline $\begin{array}{l}\text { Removal of } \\
\text { Organic } \\
\text { Complexants by } \\
\text { Supercritical } \\
\text { Extraction }\end{array}$ & Reduction in gas retention. & $\begin{array}{l}\text { Gas generation is primarily the } \\
\text { result of decomposition of the } \\
\text { organic complexants in the } \\
\text { waste. Supercritical extraction } \\
\text { removes the organic complexants } \\
\text { and reduces the gas generation } \\
\text { rate. Lower gas generation rates } \\
\text { would result in lower gas } \\
\text { fractions. }\end{array}$ & $\begin{array}{l}\text { Considered in theory by } \\
\text { Hanford. Water and carbon } \\
\text { dioxide are the primary fluids } \\
\text { used in the industrial } \\
\text { application of supercritical } \\
\text { extraction. Water can not be } \\
\text { used as the working fluid } \\
\text { with an aqueous system. } \\
\text { Carbon dioxide would } \\
\text { dissolve in the alkaline waste } \\
\text { creating addition sodium } \\
\text { carbonate. }\end{array}$ \\
\hline $\begin{array}{l}\text { Removal of } \\
\text { radioactive } \\
\text { isotopes }\end{array}$ & Reduction in gas retention. & $\begin{array}{l}\text { Removing the major radioactive } \\
\text { isotopes would eliminate } \\
\text { radiolytic gas generation. Lower } \\
\text { gas generation rates would result } \\
\text { in lower gas fractions. }\end{array}$ & $\begin{array}{l}\text { Considered in theory by } \\
\text { Hanford. The primary } \\
\text { radioactive isotopes are } \\
\text { cesium and strontium. } \\
\text { Process to recover cesium and } \\
\text { strontium from the waste } \\
\text { were operated in B Plant. }\end{array}$ \\
\hline $\begin{array}{l}\text { Separation of } \\
\text { High Molecular } \\
\text { Weight } \\
\text { Components by } \\
\text { Ultrafitration }\end{array}$ & Reduction in gas retention. & & $\begin{array}{l}\text { Considered in theory by } \\
\text { Hanford. What these high } \\
\text { molecular weight compounds } \\
\text { are is not clear. }\end{array}$ \\
\hline $\begin{array}{l}\text { Solvent } \\
\text { Extraction of } \\
\text { Select Chemical } \\
\text { Species }\end{array}$ & Reduction in gas retention. & $\begin{array}{l}\text { Removing the select chemical } \\
\text { species could lower gas } \\
\text { generation rate. Lower gas } \\
\text { generation rates would result in } \\
\text { lower gas fractions. }\end{array}$ & $\begin{array}{l}\text { Considered in theory by } \\
\text { Hanford. }\end{array}$ \\
\hline
\end{tabular}




\section{TABLE 6-1 (cont) \\ MITIGATION STRATEGIES FOR FG-1 DSTS}

\begin{tabular}{|c|c|c|c|}
\hline $\begin{array}{c}\text { Mitigation } \\
\text { Strategy }\end{array}$ & Classification & Physical Principles & History/Comments \\
\hline $\begin{array}{l}\text { Removal of } \\
\text { Aluminate }\end{array}$ & $\begin{array}{l}\text { Reduction in gas retention } \\
\text { Reduction of nonconvective } \\
\text { layer volume. }\end{array}$ & $\begin{array}{l}\text { Aluminate removal reduces the } \\
\text { mass of solids in the waste. } \\
\text { Aluminate acts as a catalyst is } \\
\text { some of the gas generating } \\
\text { reactions. Removing aluminate } \\
\text { would reduce gas generation. } \\
\text { Sludges containing solid } \\
\text { aluminates appear to retain more } \\
\text { gas than other sludges. Removing } \\
\text { aluminat: may reduce void } \\
\text { fraction. }\end{array}$ & $\begin{array}{l}\text { New mitigation concept. } \\
\text { The aluminate removal } \\
\text { process would be similar to } \\
\text { the Bayer process for the } \\
\text { commercial production of } \\
\text { alumina from bauxite. }\end{array}$ \\
\hline $\begin{array}{l}\text { Removal of } \\
\text { Sodium Carbonate }\end{array}$ & $\begin{array}{l}\text { Reduction of nonconvective } \\
\text { layer volume. }\end{array}$ & $\begin{array}{l}\text { Removing sodium carbonate } \\
\text { would reduces the mass of solids } \\
\text { in the waste. A high weight } \\
\text { fraction sodium carbonate in the } \\
\text { solids may favor buoyant } \\
\text { displacements. Removing } \\
\text { carbonate may reduce likelihood } \\
\text { of rollovers. }\end{array}$ & $\begin{array}{l}\text { New mitigation concept. } \\
\text { Sodium carbonate is a major } \\
\text { solids component in most } \\
\text { saltcake wastes. }\end{array}$ \\
\hline $\begin{array}{l}\text { Addition of } \\
\text { Mineral Forming } \\
\text { Agents }\end{array}$ & Reduction in gas retention. & $\begin{array}{l}\text { Mineral forming agents would } \\
\text { reduce the concentration of } \\
\text { dissolved aluminate. Aluminate } \\
\text { acts as a catalyst is some of the } \\
\text { gas generating reactions. } \\
\text { Removing aluminate would } \\
\text { reduc } 3 \text { gas generation. }\end{array}$ & $\begin{array}{l}\text { Considered in theory by } \\
\text { Hanford. }\end{array}$ \\
\hline $\begin{array}{l}\text { Lowering pH of } \\
\text { the Waste }\end{array}$ & Reduction in gas retention. & $\begin{array}{l}\text { Lowering the } \mathrm{pH} \text { reduces the gas } \\
\text { generation rate. Lower gas } \\
\text { generation rates would result in } \\
\text { lower gas fractions. }\end{array}$ & $\begin{array}{l}\text { Experiments with waste } \\
\text { simulants from } 1980 \text { indicate } \\
\text { that gas generation rate } \\
\text { increases with increasing } \mathrm{pH} \\
\text { The Georgia Tech waste } \\
\text { simulant experiments indicate } \\
\text { that generation rate increases } \\
\text { with decreasing hydroxide } \\
\text { concentration. }\end{array}$ \\
\hline $\begin{array}{l}\text { Hydroxide } \\
\text { Addition }\end{array}$ & Reduction in gas retention. & $\begin{array}{l}\text { Gas is retained because a } \\
\text { amorphous alumina gel is formed } \\
\text { as a result of acidification of the } \\
\text { waste due to carbon dioxide } \\
\text { production or absorption. } \\
\text { Hydroxide addition prevents the } \\
\text { formation of alumina gels. }\end{array}$ & $\begin{array}{l}\text { New mitigation concept. } \\
\text { Bubbling carbon dioxide } \\
\text { through a waste simulant } \\
\text { produced an alumina gel. } \\
\text { However, there are tanks } \\
\text { with high hydroxide } \\
\text { concentrations with } \\
\text { significant retained gas } \\
\text { inventories. }\end{array}$ \\
\hline Cooling the Waste & Reduction in gas retention. & $\begin{array}{l}\text { Cooling the waste reduces the gas } \\
\text { generation rate. Lower gas } \\
\text { generation rates would result in } \\
\text { lower gas fractions. }\end{array}$ & $\begin{array}{l}\text { Cooling the waste in SY-101 } \\
\text { resulted in larger GREs. }\end{array}$ \\
\hline
\end{tabular}


TABLE 6-1 (cont)

\section{MITIGATION STRATEGIES FOR FG-1 DSTS}

\begin{tabular}{|c|c|c|c|}
\hline $\begin{array}{l}\text { Mitigation } \\
\text { Strategy }\end{array}$ & Classification & Physical Principles & History/Comments \\
\hline $\begin{array}{l}\text { Addition of Free } \\
\text { Radical Scavenger }\end{array}$ & Reduction in gas retention & $\begin{array}{l}\text { Free radical scavengers reduce } \\
\text { the radiolysis rate. Lower gas } \\
\text { generation rates would result in } \\
\text { lower gas fractions. }\end{array}$ & $\begin{array}{l}\text { New mitigation concept. } \\
\text { Literature reports } \mathrm{G}\left(\mathrm{H}_{2}\right) \\
\text { decreases with the addition } \\
\text { of free radical scavengers. } \\
\text { Scavenger addition } \\
\text { considered in LANL's } \\
\text { analysis of gas generation for } \\
\text { Project W-320. }\end{array}$ \\
\hline Solidification & $\begin{array}{l}\text { Gas retention. generation } \\
\text { and release. }\end{array}$ & $\begin{array}{l}\text { Solidification increases the shear } \\
\text { strength. } \\
\text { Bubbles if generated are } \\
\text { prevented to be buoyant with } \\
\text { high shear strength. } \\
\text { Reduces the gas generation. } \\
\text { Freezing is an option for } \\
\text { solidification. }\end{array}$ & $\begin{array}{l}\text { New mitigation concept. } \\
\text { High risk. } \\
\text { Design and cost is unknown. }\end{array}$ \\
\hline $\begin{array}{l}\text { Mitigation of } \\
\text { Burn (MPR) }\end{array}$ & $\begin{array}{l}\text { Mitigate the consequence of } \\
\text { FG ignition. }\end{array}$ & $\begin{array}{l}\text { Adequate venting is an effective } \\
\text { method use explosion prevention } \\
\text { methods. } \\
\text { The ignition of FG is allowed but } \\
\text { the occurrence of damaging } \\
\text { pressures in the dome is } \\
\text { prevented. } \\
\text { It prevents structural damage to } \\
\text { the tank therefore large material } \\
\text { releases. }\end{array}$ & $\begin{array}{l}\text { New mitigation concept. } \\
\text { It does not provide zero } \\
\text { material release. } \\
\text { Low cost -fast schedule } \\
\text { concept. } \\
\text { Significantly reduces the } \\
\text { consequences/ }\end{array}$ \\
\hline $\begin{array}{l}\text { Dome Explosion } \\
\text { Suppression }\end{array}$ & $\begin{array}{l}\text { Mitigate the consequence of } \\
\text { FG ignition. }\end{array}$ & $\begin{array}{l}\text { Adequate explosion suppression } \\
\text { systems can be used to extinguish } \\
\text { the ignition. }\end{array}$ & $\begin{array}{l}\text { New mitigation concept. } \\
\text { It does not provide zero } \\
\text { material release. } \\
\text { Cost is unknown. } \\
\text { Significantly reduces the } \\
\text { consequences. }\end{array}$ \\
\hline
\end{tabular}




\section{PRELIMINARY RANKING}

In the previous section, a list of potential mitigation strategies was identified. There wf :e insufficient resources for each of these strategies to be fully investigated as par of this work. A methodology was developed to rank these strategies so that attention could be focused on the most promising strategies.

\subsection{Ranking Methodology}

A preliminary two-step ranking process was developed. A lengthy list of attributes was identified. Of these attributes, the following were considered most important:

- Soundness of the Principle of Operation

- Proof of Principle of Operation

- New Data on Which to Evaluate

- New Analysis Models on which to Evaluate Strategy

- Tech Status of Strategy

- Whether or not the Strategy would Preclude Retrieval

It was decided that each of the strategies would be scored on a scale of 0 to 4 on each of these attributes independently by each of the authors. After a discussion of each of the strategies, each of the 4 report authors gave a score to each of the above attributes, and the results were averaged. It was the consensus that the most important of the above attributes was the soundness of the principle of operation, followed by the proof of principle. After trying several scoring concepts, it was concluded that a preliminary score should be assigned by weighting the soundness score by a factor of 4 , the proof of principle by a factor of 2, and a factor of 1 for each of the remaining attributes.

\subsection{Preliminary Results}

The preliminary results of this ranking, sorted by preliminary score is shown in the table below. 
TABLE 7-1

PRELIMINARY RANKING OF MITIGATION STRATEGIES

\begin{tabular}{|c|c|c|c|c|c|c|c|}
\hline Mitigation Scheme & \begin{tabular}{|c|} 
Sound \\
Principle
\end{tabular} & \begin{tabular}{|c|} 
Proof of \\
Principle
\end{tabular} & $\begin{array}{l}\text { New } \\
\text { Data } \\
\end{array}$ & $\begin{array}{c}\text { New } \\
\text { Models }\end{array}$ & $\begin{array}{c}\text { Tech } \\
\text { Status }\end{array}$ & $\begin{array}{c}\text { Preclude } \\
\text { Retrieval } \\
\end{array}$ & Score \\
\hline Horizontal Jet Pump Mixing & 4.00 & 4.00 & 3.75 & 3.25 & 4.00 & 4.00 & 39.00 \\
\hline Retrieval & 4.00 & 4.00 & 3.25 & 3.00 & 3.75 & 4.00 & 38.00 \\
\hline Dilution & 4.00 & 3.50 & 4.00 & 3.75 & 2.75 & 3.75 & 37.25 \\
\hline Removal of Radioactive Isotopes & 4.00 & 3.50 & 3.00 & 2.50 & 3.50 & 4.00 & 36.00 \\
\hline Inerting Dome Space & 4.00 & 3.00 & 3.75 & 3.75 & 2.25 & 3.50 & 35.25 \\
\hline Supernatant Liquid Removal & 3.50 & 3.25 & 3.75 & 3.00 & 3.75 & 4.00 & 35.00 \\
\hline V.rtical Jet Pump Mixing & 4.00 & 2.25 & 3.50 & 2.50 & 2.25 & 4.00 & 32.75 \\
\hline Past Practice Sluicing & 4.00 & 2.00 & 3.25 & 2.25 & 3.00 & 4.00 & 32.50 \\
\hline Spark Control & 4.00 & 2.00 & 2.75 & 2.25 & 3.25 & 3.75 & 32.00 \\
\hline Heating & 2.75 & 2.75 & 3.75 & 3.75 & 1.50 & 3.75 & 29.25 \\
\hline Removal of Aluminate & 3.50 & 2.00 & 2.75 & 2.00 & 2.25 & 3.75 & 28.75 \\
\hline Organic Destruction by Heating & 3.50 & 1.75 & 3.75 & 2.50 & 1.00 & 3.75 & 28.50 \\
\hline Nonconvective Layer Recirculation & 3.75 & 1.00 & 3.25 & 2.00 & 2.00 & 4.00 & 28.25 \\
\hline Burn Mitigation (MPRs) & 1.50 & 3.25 & 4.00 & 3.50 & 4.00 & 4.00 & 28.00 \\
\hline Cooling the Waste & 3.00 & 2.25 & 3.25 & 3.25 & 1.75 & 3.00 & 27.75 \\
\hline Low Frequency Sonic Probe & 3.25 & 2.25 & 2.00 & 1.00 & 3.00 & 2.50 & 26.00 \\
\hline Water Lancing nonconvective Layer & 2.75 & 2.00 & 2.50 & 1.25 & 3.25 & 3.50 & 25.50 \\
\hline Addition of Free Radical Scavenger & 3.00 & 1.75 & 2.50 & 2.00 & 1.75 & 2.50 & 24.25 \\
\hline Mechanical Stirring & 3.50 & 1.00 & 2.50 & 1.50 & 1.25 & 2.75 & 24.00 \\
\hline Removal of Sodium Carbonate & 3.00 & 1.25 & 2.75 & 2.00 & 0.50 & 3.75 & 23.50 \\
\hline $\begin{array}{l}\text { Organic Destruction by Chemical } \\
\text { Means }\end{array}$ & 3.25 & 1.00 & 1.50 & 1.50 & 0.50 & 3.50 & 22.00 \\
\hline Dome Explosion Suppression & 2.75 & 1.50 & 0.75 & 1.25 & 1.00 & 4.00 & 21.00 \\
\hline High Frequency Sonic Probe & 2.25 & 1.50 & 2.00 & 1.00 & 3.00 & 2.50 & 20.50 \\
\hline $\begin{array}{l}\text { Surfactant Addition to Reduce } \\
\text { Bubble Attachment }\end{array}$ & 2.50 & 1.25 & 1.50 & 1.25 & 1.25 & 2.75 & 19.25 \\
\hline Solidification of the Waste & 3.25 & 1.00 & 0.50 & 0.25 & 0.50 & 2.00 & 18.25 \\
\hline $\begin{array}{l}\text { Surfactant Addition to Modify } \\
\text { Rheology }\end{array}$ & 1.75 & 1.00 & 1.25 & 1.25 & 1.25 & 3.25 & 16.00 \\
\hline Air Lancing nonconvective Layer & 1.00 & 1.00 & 2.00 & 1.00 & 3.25 & 2.75 & 15.00 \\
\hline Steam Lancing nonconvective Layer & 1.25 & 1.00 & 1.75 & 1.00 & 1.75 & 2.75 & 14.25 \\
\hline Lancing with N2 & 1.00 & 1.00 & 2.00 & 1.00 & 2.50 & 2.75 & 14.25 \\
\hline Nitrogen Sparging & 1.00 & 1.00 & 2.00 & 2.25 & 0.50 & 2.75 & 13.50 \\
\hline Lowering pH of the Waste & 1.50 & 0.50 & 1.75 & 1.00 & 0.75 & 2.75 & 13.25 \\
\hline Heat to Atmospheric Boiling Point & 1.50 & 1.00 & 0.50 & 0.50 & 0.75 & 2.75 & 12.50 \\
\hline Solvent Extraction of Select Species & 1.50 & 0.50 & 1.00 & 1.00 & 0.75 & 2.50 & 12.25 \\
\hline Addition of Mineral Forming Agents & 1.00 & 0.75 & 1.50 & 0.75 & 1.00 & 2.25 & 11.00 \\
\hline Hydroxide Addition & 0.50 & 0.75 & 1.25 & 0.50 & 0.75 & 3.00 & 9.00 \\
\hline
\end{tabular}

TABLE 7-1 (cont)

PRELIMINARY RANKING OF MITIGATION STRATEGIES 


\begin{tabular}{|l|c|c|c|c|c|c|c|}
\hline \multicolumn{1}{|c|}{ Mitigation Scheme } & $\begin{array}{c}\text { Sound } \\
\text { Principle }\end{array}$ & $\begin{array}{c}\text { Proof of } \\
\text { Principle }\end{array}$ & $\begin{array}{c}\text { New } \\
\text { Data }\end{array}$ & $\begin{array}{c}\text { New } \\
\text { Models }\end{array}$ & $\begin{array}{c}\text { Tech } \\
\text { Status }\end{array}$ & $\begin{array}{c}\text { Preclude } \\
\text { Retrieval }\end{array}$ & Score \\
\hline $\begin{array}{l}\text { Removal of Organic Complexants by } \\
\text { Supercritical Extraction }\end{array}$ & 0.25 & 0.25 & 0.75 & 0.25 & 0.75 & 2.00 & 5.25 \\
\hline Separation by Ultrafiltration & 0.25 & 0.25 & 0.25 & 0.25 & 0.50 & 2.50 & 5.00 \\
\hline
\end{tabular}


Based on the above ranking results, several mitigation strategies were eliminated from further analysis. The important attributes that was not considered in the first pass were added in the second pass included cost and schedule. It was not felt a single estimate for cost and schedule wrs appropriate, since for some tanks, a proposed mitigation strategy might be employed with minimal cost and minimal schedule delays whereas this might not be the case for other tanks. As an example, consider dilution. If a tank had sufficient headspace, simply adding water to the waste (either by pouring it on top of the waste or perhaps by lancing it in to the nonconvective layer) could be a relatively inexpensive mitigation strategy. On the other hand, if the tank was nearly full, supernate would need to be removed prior to dilution. The cost of supernate removal was estimated to be more expensive in this case, and the cost would depend on whether or not a suitable pump was in the tank, whether it would be necessary to evaporate the removed supernate, and whether equipment would need to be removed from the central pump pit prior to installation of the transfer pump, and so forth.

Another round of discussions was held in which consensus estimates of both optimistic and pessimistic schedule estimates were developed for the most promising of the mitigation strategies. The cost estimates were not based on a detailed study, and should be considered order-of-magnitude estimates.

A total score was computed by taking the preliminary score and dividing it by the estimated cost and dividing the result by the estimated time requirements. The result, for both the pessimistic and optimistic estimates are shown in the following tables. 
TABLE 7-2

PRELIMINARY RANKING OF MITIGATION STRATEGIES BASED ON PESSIMISTIC COST AND SCHEDULE ESTIMATES

\begin{tabular}{|c|c|c|c|c|}
\hline Mitigation Scheme & $\begin{array}{l}\text { Preliminary } \\
\text { Score }\end{array}$ & $\begin{array}{c}\text { Pessimistic } \\
\text { Cost (M\$) }\end{array}$ & $\begin{array}{c}\text { Pess:mistic } \\
\text { Schedule } \\
\text { (Years) }\end{array}$ & Total Score \\
\hline$\overline{\text { Burn Mitigation (MPRs) }}$ & 28.00 & 1.00 & $\overline{0.50}$ & 56.00 \\
\hline Inerting Dome Space & 35.25 & 2.00 & 1.00 & $\overline{17.63}$ \\
\hline Spark Control & 32.00 & 2.00 & 1.00 & 16.00 \\
\hline Low Frequency Sonic Probe & 26.00 & 2.00 & 1.00 & 13.00 \\
\hline $\begin{array}{l}\text { Pump Mixing } \\
\text { (Horizontal Jet Mixing) }\end{array}$ & 39.00 & 15.00 & 0.88 & 2.94 \\
\hline Cooling the Waste & 27.75 & 15.00 & 1.00 & 1.85 \\
\hline Supernatant Liquid Removal & 35.00 & 10.00 & 2.00 & 1.75 \\
\hline $\begin{array}{l}\text { Nonconvective Layer } \\
\text { Recirculation }\end{array}$ & 28.25 & 10.00 & 2.00 & 1.41 \\
\hline Heating & 29.25 & 10.00 & 3.00 & 0.98 \\
\hline$\overline{\text { Dilution }}$ & 37.25 & 20.00 & 2.00 & 0.93 \\
\hline $\begin{array}{l}\text { Pump Mixing } \\
\text { (Vertical Jet Mixing) }\end{array}$ & 32.75 & 20.00 & 2.00 & 0.82 \\
\hline Past Practice Sluicing & 32.50 & 20.00 & 2.00 & 0.81 \\
\hline $\begin{array}{l}\text { Organic Destruction by } \\
\text { Heating }\end{array}$ & 28.50 & 20.00 & $\overline{3.00}$ & 0.48 \\
\hline Retrieval & 38.00 & 40.00 & 5.00 & 0.19 \\
\hline $\begin{array}{l}\text { Removal of Radioactive } \\
\text { Isotopes }\end{array}$ & 36.00 & 40.00 & 5.00 & 0.18 \\
\hline Removal of Aluminate & 28.75 & 40.00 & 5.00 & $\overline{0.14}$ \\
\hline
\end{tabular}


TABLE 7-3 PRELIMINARY RANKING OF MITIGATION STRATEGIES BASED ON
OPTIMISTIC COST AND SCHEDULE ESTIMATES

\begin{tabular}{|l|c|c|c|c|}
\hline \multicolumn{1}{|c|}{ Mitigation Scheme } & $\begin{array}{c}\text { Preliminary } \\
\text { Score }\end{array}$ & $\begin{array}{c}\text { Optimistic } \\
\text { Cost (M\$) }\end{array}$ & $\begin{array}{c}\text { Optimistic } \\
\text { Schedule } \\
\text { (Years) }\end{array}$ & Total Scorc \\
\hline Dilution & 37.25 & 1.00 & 0.50 & 74.50 \\
\hline Supernatant Liquid Removal & 35.00 & 1.00 & 0.50 & 70.00 \\
\hline Burn Mitigation (MPRs) & 28.00 & 1.00 & 0.50 & 56.00 \\
\hline Past Practice Sluicing & 32.50 & 2.00 & 0.50 & 32.50 \\
\hline Heating & 29.25 & 1.00 & 1.00 & 29.25 \\
\hline $\begin{array}{l}\text { Nonconvective Layer } \\
\text { Recirculation }\end{array}$ & 28.25 & 2.00 & 0.50 & 28.25 \\
\hline Inerting Dome Space & 35.25 & 2.00 & 1.00 & 17.63 \\
\hline Spark Control & 32.00 & 2.00 & 1.00 & 16.00 \\
\hline Low Frequency Sonic Probe & 26.00 & 2.00 & 1.00 & 13.00 \\
\hline $\begin{array}{l}\text { Pump Mixing (Horizontal Jet } \\
\text { Mixing) }\end{array}$ & 39.00 & 10.00 & 0.88 & 4.41 \\
\hline $\begin{array}{l}\text { Cooling the Waste } \\
\text { Pump Mixing (Vertical Jet } \\
\text { Mixing) }\end{array}$ & 27.75 & 10.00 & 1.00 & 2.78 \\
\hline $\begin{array}{l}\text { Organic Destruction by } \\
\text { Heating }\end{array}$ & 28.50 & 20.00 & 2.00 & 0.82 \\
\hline Removal of Aluminate & 28.75 & 40.00 & 3.00 & 0.24 \\
\hline $\begin{array}{l}\text { Retrieval } \\
\text { Removal of Radioactive } \\
\text { Isotopes }\end{array}$ & 38.00 & 40.00 & 5.00 & 0.19 \\
\hline
\end{tabular}

Based on the above results, several mitigation strategies appear worthy of more detailed analysis, including: dilution, supernate removal, heating, inerting dome space, pump mixing, burn mitigation. The rest of mitigation strategies listed in Table. 7.2 and 7.3 will be discussed qualitatively.

1 - G. D. Johnson, W.B. Barton, R. C. Hill, J. W. Brothers, S. A. Bryan, P. A. Gauglitz, L. R. Pederson, C. W. Steward, L. H. Stock, "Flammable Gas Project Topical Report," HNF-SP-1193, Rev. 2, UC-2030, January 1997. 
2 - H. Babad, J. L. Deichman, B. M. Johnson, D. K. Lemon, D. M. Strachan, "Mitigation/Remediation Concepts for Hanford Site Flammable Gas Generating Waste Tanks," WHC-EP-0516, UC-510, Westinghouse Hanford Company, April 1992.

3 C. W. Stewart, L. A. Schienbein, J. D. Hudson, E. J. Eschbach, D. L. Lessor, "Assessment of Selected Alternative Mitigation Concepts for Hanford Flammable Gas Tanks," Pacific Northwest Laboratory report, PNL-10105, UC-510, September 1994.

4- M. Grigsby and C. E. Leach, "Flammable Gas/Slurry Growth Unreviewed Safety Question: Justification for Continued Operation for the Tank Farms at the Hanford Site," WHC-SD-WM-JCO-007, Rev. 0, 1996.

5 - D. S. Trent and T. E. Michener, "Numerical Simulation of Jet Mixing Concepts in Tank 241-SY-101," Pacific Northwest National Laboratory report, PNNL-8559, UC505, 510 (March 1993)

6 - C. W. Stewart et. al, "Mitigation of Tank 241-SY-101 by Pump Mixing: Results of Full-Scale Testing, "Pacific Nortwest National Laboratory report, PNL-9959, UC510 (June 1994).

7 - M. R. Powell, Y. Onishi, R. Shekarriz, "Research on Jet Mixing of Setteled Sludges in Nuclear Waste Tanks at Hanford and Other DOE Sites: A Historical Perspective," Pacific Northwest National Laboratory, PNNL-11686, UC-721, September 1997.

8- A. Shekarriz, K. J. Hammad, M. R. Powell, "Evaluation of Scaling Correlations for Mobilization of Double-Shell Tank Waste," Pacific Northwest National Laboratory report, PNNL-11737, (September 1997).

9- B. M. Hanlon, "Waste Tank Summary Report for Month Ending March 31, 1996," Westinghouse Hanford Company report WHC-EP-0182-96.

10 -J. R. Abbott, and C. Unal, "Sampling Ability of the In-Situ Voidmeter Instrument," Los Alamos National Laboratory letter report TSA-6-94-316, Nov. 16, 1994. 
11- L. H. Sullivan st. al., "A Safety Arsessment for Proposed Pump Mixing Operations to Mitigate Episodic Gas Releases in Tank 214-SY-101, Hanford Site, Richland, Washington," LA-UR-92-3196, Rev. 14.

12 - . W. Stewart, C. L. Shepard, J. M. Alzheimer, T. I. Stokes, G. Terrones, "In Situ Determination of Rheological Properties and Void Fraction in Hanford Waste Tank 241-SY-101," Pacific Nortwest Laboratory, PNL-10682, UC-510, (Agust 1995).

13 . A. Shekkariz, D. R. Rector, L. A. Mahoney, M. A. Chieda, J. M. Bates, R. E. Bauer, N. S. Cannon, B. E. Hey, C. G. Linschooten, F. J. Reitz, and E. R. Siciliano, "Composition and Quantities of Retained Gas Measured in Hanford Waste Tanks 241-AW-101, A-101, AN-105, AN-104, and AN-103," Pacific Northwest National Laboratory report PNNL-11450, Rev. 1, March 1997.

14 -"Tank Characterization Report for Double-Shell Tank 241-AN-103," Project Hanford Management Contractor report HNF-SD-WM-ER-702, Rev. 0, August 1997.

15 -. T. Hu, L. Shelton, and T. Welsh, "Tank Characterization Report for DoubleShell Tank 241-AN-104," Project Hanford Management Contractor report HNF-SDWM-ER-690, Rev. 0, August 1997.

16 - J. Jo, "Tank Characterization Report for Double-Shell Tank 241-AN-105," Project Hanford Management Contractor report HNF-SD-WM-ER-678, Rev. 0, August 1997.

17 - T. Welsh, Tank 241-AW-101 Characterization Results," Westinghouse Hanford Company report WHC-SD-WM-TRP-055, December 1991.

18 - P. A. Meyer, M. E. Brewster, S. A. Bryan, G. Chen, L. R. Pederson, C. W. Stewart, and G. Terrones, "Gas Retention and Release Behavior in Hanford Double-Shell Waste Tanks," Pacific Northwest National Laboratory report PNNL-11536, Rev. 1, May 1997. 
19 - W. R. Bohl, "Remarks on Void Development in Hanford Double-Shell Tanks," Los Alamos National Laboratory report LA-UR-97-3823, September 1997.

20 -B. Kubic and G. Pillay, "Data Reconciliation Study of Tank 241-AN-103 at the Hanford Site," Los Alamos National Laboratory report, LA-UR-97-3955, September 30, 1997.

21 -B. Bohl, "Some Remarks on Void Development in Hanford DST Sludge," Los Alamos National Laboratory report, LA-UR-97-3823, September 30, 1997.

22 -C. Unal et. al, "A Safety Assessment of Rotary Mode Core Sampling in Flammable Gas Single Shell Tanks: Hanford Site, Richland Washington," WHCSD-WM-SAD-035, Rev. 0a, August 1996.

23- K. Pasamehmetoglu, et. al. "A Safety Assessment of Proposed Pump Mixing Operations to Mititage Episodic Gas Releases in Tank 241-SY-101: Hanford Site, Richland, Washington," Los Alamơs National Laboratory report, LA-UR-92-3196, Rev. 15, 1996.

24. P. A. Meyer, M. E. Brewster, S. A. Bryan, G. Chen, L. R. Pederson, C. W. Steward, G. Terrones, "Gas Retention and Release Behavior in Hanford DoubleShell Waste Tanks," Pacific Nortwest National Laboratory, PNNL-11536, Rev. 1, UC2030 (May 1997). 
M98004331

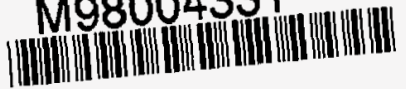

Report Number (14) LA- $L R--97-4912$

Publ. Date (11) $1997 / 1$

Sponsor Code (18) DOE/MA, XF

UC Category (19) uC-940, DOE/ER

DOE 